\title{
Segunda mirada desde otro planeta. Lazarillo de Tormes como prueba (o apuesta) sobre la aplicabilidad del neolachmannismo a tradiciones modernas*
}

\author{
Paolo Trovato \\ Universidad de Ferrara
}

Título: Otra mirada desde otro planeta Lazarillo de Tormes como prueba (o apuesta) sobre la aplicabilidad del neolachmannismo a tradiciones modernas.

Resumen: El presente artículo, firmado por un romanista que consagra buena parte de sus trabajos y de sus días a la Comedia de Dante, pasa respetuosa y — en lo posible — concienzuda revista a las ediciones críticas del Lazarillo de Tormes en el haber de Jaime Moll, Jesús Cañas, Félix Carrasco, Aldo Ruffinatto, Alberto Blecua y Francisco Rico, así como a las últimas apostillas de Arturo Rodríguez López-Abadía y Arturo Rodríguez López Vázquez, para proponer un nuevo estema - de cuńo neolachmanniano- para la obra cumbre de la picaresca espańola.

Palabras clave: Lazarillo de Tormes, Edición Crítica, Estema, Novela picaresca.

Fecha de recepción: 31/5/2016.

Fecha de aceptación: 22/6/2016.
Title: A Second View from another Planet. Lazarillo de tormes as a text (or Bet) about the Applicability of the Lachmann's Method to Modern Textual Traditions.

Abstract: This paper, signed by a textual scholar who devotes much of his work and his days to the Comedy of Dante, reviews respectfully and — as far as possible - conscientiously the critical editions of Lazarillo de Tormes by Jaime Moll, Jesús Cañas, Félix Carrasco, Aldo Ruffinatto, Alberto Blecua and Francisco Rico, as well as the last contributions of Arturo Rodríguez LópezAbadía and Arturo Rodríguez López Vázquez, in order to propose a new stemma for the masterpiece of the Spanish Picaresque.

Key words: Lazarillo de Tormes, Critical Edition, Stemma, Picaresque Novel.

Date of Receipt: 31/5/2016.

Date of Approval: 22/6/2016.

* Traducción de Rafael Bonilla Cerezo (desde Siam, tras una regocijada plática con el faraón de Egipto).

Agradezco a Carlo Beretta, Luciano Formisano, Giuseppe Mazzocchi y Paolo Tanganelli sus preciosas sugerencias a una versión previa de este artículo. 
A Francisco Rico, que me ha hecho entender a Petrarca y redescubrir la literatura española

Hay que evitar que los inestimables beneficios de la duda científica se avinagren en una metafísica de la desesperación científica.

Albert Henry

Democracy is the worst form of government except for all the others

Winston Churchill

\section{Preliminares}

Los presupuestos, decididamente casuales, de esta segunda incursión en el canon de la tradición literaria española por parte de un filólogo proveniente de otro planeta (acabo de escribir un manual de crítica textual neolachmanniana bastante amplio, si bien atípico) se pueden recabar en un breve intercambio de correos electrónicos durante el verano de $2015^{2}$. El 15 de junio, escribí:

\section{Querido P.,}

Estoy releyendo tu Lazarillo. Tendrás seguramente razón tú, pero me gustaría probar a hacer de advocatus diaboli. ¿Podría disponer de copias digitales de las cuatro ediciones de 1554?

El 16 de junio de 2015, P. respondía:

¡Hazlo, hazlo, prueba! Hace tiempo que te desafié a hacerlo. Frustra lavorabis... Me hallo de viaje o muy ocupado hasta el 28. Después, te procuro los PDFs.

2 El manual es el siguiente: Paolo Trovato, Everything You Always Wanted to Know about Lachmann's Method. A Non-Standard Handbook of Genealogical Textual Criticism in the Age of Post-Structuralism, Cladistics, and Copy-Text, Padova, libreriauniversitaria. it, 2014. Mi primer asedio, relativo al Libro del Buen Amor, se publicó bajo el título de "Sguardi da un altro pianeta al testo (e al metro) del Libro de buen amor", Rivista di Filologia e Letteratura Ispaniche, 17 (2014), pp. 41-86. 
Como resulta fácil suponer, P., o sea, Paco, es el amigo Francisco Rico, de quien hace más de tres décadas que admiro sus múltiples competencias, la calidad de su escritura, su inteligencia luciferina, aun cuando, como se antoja fácil adivinar, yo no comparta su aspiración de segar hasta la misma raíz, a fuer de contraponer experiencias diversas y de afirmar su escasa aplicabilidad, el neolachmannismo de escuela italiana: un proyecto puntualmente diagnosticado por un amigo suyo $-\mathrm{y}$, gracias a él, también mío-, Alberto Blecua ("un muy querido amigo [...], Francisco Rico, ha lanzado las saetas de su Némesis vengadora contra la crítica textual"; "desde un tiempo a esta parte, circula una corriente antilachmanniana, sobre todo en Italia, alentada por la rivista Ecdotica, excelente sin duda, pero un tanto refractaria a quienes como Contini, maestro querido, tanto han hecho para que las ediciones apliquen con rigor el método filolólogico..." $)^{3}$.

Por consiguiente, mi trabajo apuntará simplemente a cotejar la vigencia de las clasificaciones genealógicas que en los últimos años se han propuesto para la tradición del Lazarillo, sin ninguna pretensión de exhaustividad bibliográfica (por otra parte casi irrealizable, dado el océano de estudios disponibles) y sin rozar ni mínimamente los numerosos problemas suscitados por la densísima novela, empezando por el nombre de su autor — según se sabe, hombre de buena formación humanística y de amplias lecturas, incluidos muchos italianos, entre los cuales se hallaba Masuccio Salernitano-.

Adelanto sin más rodeos que, cualesquiera que sean las hipótesis reconstructivas de los estudiosos, el orden textual del Lazarillo no ha sido ni podrá ser dañado apenas por las arbitrariedades de las diferentes escuelas filológicas. Por razones diversas, pero solidísimas, ninguna de las cuatro ediciones más antiguas que han llegado hasta nosotros $(\mathrm{A}=$ Alcalá de Henares, con fecha del 26 de febrero de 1554; $\mathrm{B}=$ Burgos, que data del mismo año; $\mathrm{C}$ = Amberes, asimismo coetánea; y $\mathrm{M}=$ Medina del Campo, que también se remonta a 1554 , en concreto al 1 de marzo) puede identificarse con la primera edición de la obra o considerarse copia de una de las otras tres (daré por asumido este punto, excepción hecha, y lo veremos después, de $\mathrm{C}$, que es preciso reevaluar, y de la reciente e impecable de-

3 Alberto Blecua, "Defensa e ilustración de la crítica textual" (2009), en Estudios de crítica textual, Madrid, Gredos, 2012, pp. $35-46$ (pp. 36 y 45-46). 
mostración de la independencia de $\mathrm{B}$, en el haber de Blecua $)^{4}$.

Por lo que atañe tanto al plano cronológico como al plano textual, las cuatro ediciones están necesariamente muy próximas a la princeps $\mathrm{P}^{*}$, que dataría de unos ańos atrás (¿1553, 1552 o antes?), de la cual, como ocurre en el caso de tantas obras de vasto consumo ( $¡$ y nunca la metáfora vino más al pelo!), no sobrevive ni siquiera una copia ${ }^{5}$. De acuerdo una vez más con Blecua, "el Lazarillo es obra sin apenas problemas textuales prácticos, pero de gran interés teórico y metodológico" ${ }^{\text {. }}$

4 Listas muy amplias, si bien ametódicas, de los errores y de las variantes de cada edición respecto de las otras (y algunos de dichos casos son ciertamente separativos) las ofrece, entre otros, Jesús Cañas Murillo, "Un Lazarillo de Medina del Campo: peculiaridades y variantes de una edición desconocida de 1554", Anuario de Estudios Filológicos (1996), pp. 91-134 (pp. 97-100, etcétera).

5 Como se sabe, la pérdida de todos los ejemplares de una tirada (a mediados del Quinientos no menos de 400 o 500 copias, y más a menudo 800 o 1000) es cualquier cosa menos raro en obras de gran popularidad (baste recordar el caso de la princeps del Innamorato de Boiardo, o, para la tradición española, los ejemplos discutidos por Alberto Blecua, Manual de critica textual, Madrid, Castalia, 1983, pp. 187-189, en un epígrafe que se titula precisamente "Impresos perdidos"). Ciñéndonos al Lazarillo, A y $\mathrm{M}$ se conservan en un solo ejemplar; B, en tres copias; $\mathrm{C}$, en una decena. Además, en 1559 el Lazarillo acabó en el Índice de libros prohibidos y M se salvó solo porque fue tapiado junto con otros títulos prohibidos que formaban parte del acervo de su propietario. No se puede ni se debe excluir, en suma, que además de la princeps y de otro par de ediciones hoy ilocalizables cuya existencia viene sugerida por el estema, también otras ediciones de los ańos cincuenta se hayan perdido en su totalidad. El hecho mismo, ya subrayado por los estudiosos, de que el editor de A decida ofrecer una segunda edición con añadidos — como era común cuando se intentaba despertar el interés del público sobre una obra que había gozado ya de una larga difusión- obliga más bien a conjeturar que otras ediciones aparecieron bastante antes del 26 de febrero de 1554 .

6 Alberto Blecua, "La edición del Lazarillo de Medina del Campo y los problemas metodológicos de su filiación" (2003), en Estudios de crítica textual, pp. 285-301 (p. 297). En su ensayo de 2003, Blecua vuelve — con novedades de calado- sobre los problemas de la tradición del Lazarillo, que había ya abordado en su edición de 1972, anterior más de una veintena de ańos al descubrimiento de la única copia de M. Véase La vida de Lazarillo de Tormes, ed. Alberto Blecua, Madrid, Castalia, 1972, luego reeditada en 2011. 


\section{2. "UNA CORRIENTE ANTILACHMANNIANA..."}

Como para ajustar cuentas con anteriores trabajos suyos sobre la tradición del $\mathrm{Lazarillo}^{7}$, Rico hace gala repetidas veces de su ya incontenible anti(neo)lachmannismo en los paratextos de su reciente y muy notable edición de la estupenda novela, la cual fue publicada con un rico comentario, en 2011, dentro de la colección Biblioteca Clásica de la Real Academia Española ${ }^{8}$; por más que no faltaran ( $₫$ o precisamente porque no faltaban?) ediciones neolachmannianas del Lazarillo nada despreciables, y sin embargo indudablemente superadas. Bastará citar, en concreto, la de Blecua (que, como he indicado, no pudo tomar en consideración el testimonio M, descubierto solo en 1992 y sumado a los debates entre filólogos a partir de 1995); y la de Ruffinatto (que vino acompańada por un "estudio narratológico" muy atento a los posibles enmascaramientos de la "dimensión erótica") 9 .

Ofrezco a continuación una pequeña antología de las provocaciones de Rico — perdón, de las opiniones_-, sin duda sugestivas, pero difíciles de compartir:

Cuando la ratio typographica se deja identificar, como en los ejemplos recién citados, proporciona un criterio editorial cuyo grado de certeza es generalmente superior a cualquier otro. Buena prueba de ello son los intentos de establecer la filiación de las impresiones primitivas fundados en el viejo método de la agrupación por supuestos errores comunes: con los mismos datos, cada estudioso llega a un estema distinto (p. 199, las cursivas son mías).

7 Dejando a un lado intervenciones notables, pero de menor extensión, Rico publicó en 1967, es decir, en una época todavía filológicamente desabrida, si no precientífica, una primera edición del Lazarillo en la cual se privilegia B: La novela picaresca española. I, Barcelona, Planeta, 1967. Una segunda edición al cuidado de Rico apareció en 1987: Lazarillo de Tormes, Madrid, Cátedra, 1987. Ambas han sido frecuentemente reimpresas.

8 Lázaro de Tormes, Lazarillo de Tormes, ed. Francisco Rico, Madrid, Real Academia Española, 2011.

9 La vida de Lazarillo de Tormes, ed. Alberto Blecua, 1972 (2011); Aldo Ruffinatto, Las dos caras del "Lazarillo": texto y mensaje, Madrid, Castalia, 2000; La vida de Lazarillo de Tormes, ed. Aldo Ruffinatto, Madrid, Castalia, 2001. 
Todos esos estemas (y otros justificables) pueden explicar la mayoría de las variantes: depende de la lección del arquetipo que propongan y de los testimonios ignotos que postulen. Una de las razones de la paradoja está en que para discernir y luego relacionar los presuntos errores los estudiosos normalmente se basan sólo en disputables apreciaciones subjetivas de semántica o estilo, de modo que las suposiciones inseguras producen en cascada posteriores suposiciones cada vez más inseguras (p. 201, las cursivas son mías).

De la primera a la última divergencia [...], las ediciones de 1554 plantean problemas textuales que no se dejan resolver con un criterio único. [...] En particular con nuestra novela, al editor no le queda sino proceder caso por caso, valorando en cada instancia la génesis más presumible de la lección y, sobre todo, su eficacia en el contexto. El resultado será forzosamente una edición ecléctica (p. 205, las cursivas son mías).

No es seguro, ciertamente, ni da más que engañosas apariencias de seguridad el centenario método lachmaniano, que en España fue beneficioso en su momento y hoy resulta más bien una rémora. Una amplia bibliografía [...] ha dejado claro que regularmente no es válido para los textos del linaje del Lazarillo: textos de la Edad Moderna, de tradición impresa y con transmisores de una competencia lingüística y cultural equiparable a la de los autores (pp. 297-208, las cursivas son mías). Los cuatro estemas distintos que se han propuesto tras aparecer la edición de Medina del Campo (p. 200) certifican que tot homines lachmanniani, tot sententiae [...]. Los errores comunes, que fundamentan la teoría, en la práctica o no están, o no se dejan ver, o no sirven para filiar los testimonios [...]. Eligiendo como guías errores que no lo son inequivocamente e introduciendo los oportunos sifones (como en los árboles genealógicos), cualquier estema es posible (p. 208, las cursivas son mías, exceptuando las del "adagio latino").

La idea esencial de Rico es que con los textos modernos la ratio typographica sugerida por la filología material es más poderosa que la lógica neolachmanniana. ¿Pero es cierto? Como sabemos, en un texto de buena calidad literaria y lo bastante largo, la distribución de los errores (o sea, de las lecciones que con toda probabilidad no podían figurar en el llamado original) ofrece indicios útiles para reconstruir un diagrama (el stemma codicum). Y usado cum grano salis, es decir, sin excesos de mecanicismo, el 
estema nos permite reducir al mínimo el eclecticismo de los editores. El método genealógico, significativamente afinado por los neolachmannianos tras el cisma de Bèdier, facilita a menudo la individuación del testimonio menos alejado del origen de la tradición, al cual conviene atenerse en caso de adiaforía entre las variantes, y permite, gracias a la ley de la mayoría y a un empleo juicioso de la conjetura, aproximarse a un texto incluso más próximo al original por lo que se refiere a la sustancia textual (es decir: en el caso de oposiciones como deyuso / desuso o experiencia / experanza).

Sin embargo, en lo tocante a las grafías y a la fonomorfología, que varían libremente según los hábitos, la cultura y la procedencia de los copistas (turar / durar y similares), por regla general no se puede hacer otra cosa sino reproducir el sistema, o mejor — con Cesare Segre-, el diasistema lingüístico en el texto asumido como punto de partida para la reconstrucción, renunciando así a los delirios de omnipotencia de nuestros bisabuelos (por ejemplo, Wendelin Foerster, o el mismo Gaston Paris), que pretendían reconstruir a tiro hecho el aspecto lingüístico de los textos antiguos. (En la tradición italiana, la copia verosímilmente menos alejada y asumida como punto de partida se llama de modo no del todo afortunado texto o manuscrito base, pero huelga decir que se trata de una noción del todo distinta de aquella otra, y por desgracia homónima, que emplean otras escuelas filólogicas. Por esta razón, cada vez más veo con mejores ojos la propuesta de Lino Leonardi, que se decanta por llamar "manuscrito de superficie" al testimonio seguido por la faceta lingüística ${ }^{10}$.

Justo a propósito de un estema cuatripartito del Lazarillo según el cual A B C y M descenderían, cada uno de ellos de forma independiente, de la perdida princeps, Blecua comenta con toda la razón, si lo he entendido bien, que

se trata del stemma al que llega Jaime Moll de acuerdo con la crítica bibliográfica o material. La crítica textual es, en este sentido, mucho más operativa. Es imposible que dos textos presenten errores comu-

10 Lino Leonardi, "Il testo come ipotesi (critica del manoscritto-base)", Medioevo romanzo, 35 (2011), pp. 5-34; Paolo Trovato, Everything You Always Wanted to Know about Lachmann's Method, ad indicem. 
nes o lecturas contradictorias con relación a los otros $\operatorname{dos}^{11}$.

Me atrevo a atenuar, prudentemente, la eficacia de los criterios neolachmannianos a los que Blecua parece aludir, y reformulo con mucha libertad sus observaciones:

Si dentro de una tradición se pueden individuar una serie de errores comunes a dos o más testimonios, la eventualidad de que se trata de acuerdos casuales es tanto más improbable cuanto más amplia sea la serie de los acuerdos que innovan.

Si no me engaño, incluso después de mis apostillas, el sentido del discurso de Blecua no cambia en lo esencial. Se trataría apenas de añadir que, sobre todo cuando discrimina errores que considera significativos, el filólogo tiene el deber de explicar por qué a su juicio cierta variante es inferior a otra y no puede ser original. Cuanto más persuasivos sean los argumentos al respecto, cuanto más sus «apreciaciones de semántica o estilo» —fatalmente subjetivas, pero no necesariamente risibles o infundadas - asumirán las hechuras de breves teorías científicas, falsables o confirmables a la manera de Popper, tanto más sólido será el estema que derive de ellos.

\section{LA SOMBRA DE BÉdier}

Al menos en un punto los razonamientos de Rico recuerdan a un célebre paralogismo de Bédier. Si no resulta posible elegir entre los muchos estemas posibles del Lai de l'ombre (o, en nuestro caso, del Lazarillo), significa que el método es inadecuado. En realidad, las variables que entran en juego en una tradición manuscrita son tantas y tales (empezando por la calidad textual de las copias supervivientes) que es posible que el más que probado método de los errores comunes no sea aplicable con éxito

11 Jaime Moll, "Hacia la primera edición del Lazarillo", en Actas del IV Congreso Internacional de la Asociación Internacional del Siglo de Oro (AISO) (Alcalá de Henares, 22-27 de julio de 1966), eds. María Cruz García de Enterría, Alicia Cordón Mesa, Alcalá de Henares, Universidad de Alcalá de Henares, 1988, II, pp. 1049-1055; Alberto Blecua, "La edición del Lazarillo de Medina del Campo", p. 289. 
a la tradición de ciertas obras; sin embargo, eventuales y circunscritas defaillances de la técnica editorial (que se revelarán como tales solo a posteriori, gracias a las verificaciones de uno o más investigadores autónomos) no son evidentemente generalizables. Como recuerdo en clase al menos una vez al año, un amigo ha tenido la mala fortuna de ser operado de hemorroides por un cirujano que ignoraba o se había olvidado de que en dichas intervenciones conviene incidir ligeramente en la musculatura del esfínter para evitar que se suelten los puntos: es decir, que mi pobre amigo se ha visto obligado en menos de una semana a sufrir una segunda y a la postre dolorosa intervención. Pero la incompetencia de uno o de $n$ cirujanos no significa que la medicina occidental sea in toto inútil ni que debamos recurrir a un curandero.

Además, en palabras de Whitehead y Pickford, "Bédier's own explanation of the preponderance of two-branch stemmata implied no radical defect in the method but assumed that it was almost universally misapplied"12. En cualquier caso, en el 2004 alcancé a explicar, con la decisiva ayuda de un físico nuclear, por qué en las tradiciones antiguas y medievales los estemas bipartidos son más frecuentes; y en el 2013 he publicado un artículo sobre el Lai de l'ombre en el cual llegué a un estema muy distinto - $-y$, si no me equivoco, mejor fundado- que los experimentos del genial pero presuroso Maestro francés. Mientras no se demuestre lo contrario, incluso la tradición del Lai de l'ombre es clasificable con instrumentos de tipo neolachmanniano ${ }^{13}$.

A mi juicio, y diría (a juzgar por la cantidad de buenos estudios y ediciones disponibles) que no solo a mi juicio, los límites del llamado método de Lachmann no son de tipo cronológico (autores clásicos y medievales $v$ s autores modernos) y no dependen tampoco del medium al cual se confía la transmisión (manuscritos vs impresos). Para mantenernos dentro de la casuística que me resulta más familiar, varias de las tesis

12 Frederick Whitehead y Cedrick E. Pickford, "The Introduction to the Lai de l'Ombre: Sixty Years later", Romania, 94 (1973), pp. 145-156 (p. 149).

13 Vincenzo Guidi y Paolo Trovato, "Sugli stemmi bipartiti. Decimazione, asimmetria e calcolo delle probabilità", Filologia italiana, 1 (2004), pp. 9-48; Paolo Trovato, "La tradizione manoscritta del «Lai de l'ombre». Riflessioni sulle tecniche d'edizione primonovecentesche", Romania, 131 (2013), pp. 338-380, que es preciso integrar con L'Ombre de Bédier cent ans après (Bruxelles, 7-9 novembre 2013), en prensa. 
que he dirigido clasificaron con relativa facilidad las ediciones del Fiore di virtù y del Decameron impresas en el XV y en el XVI. Yo mismo no he encontrado grandes dificultades para ofrecer un estema de las tradiciones, muy nutridas, de La Arcadia de Sannazaro, del Aminta de Tasso y del libreto rossiniano de El turco en Italia (solo en el caso de Tasso la tradición está formada asimismo por algún manucrito). Mi colega Valentina Gritti ha clasificado de manera impecable la tradición dieciochesca de los Puntigli domestici de Goldoni. Por citar solo algunos ejemplos.

Como acabo de mencionar, uno de los mayores apuros del método de los errores comunes es, en todo caso, el de no ser aplicable de manera fructífera a autores modestos y estilísticamente poco caracterizados, pero para nuestra fortuna el autor del Lazarillo es un gran escritor (ciertamente, como se ha observado ya, "no hay en nuestra novela dos frases seguidas que no nos admiren con un acierto en la formulación, con una elegancia, con un rasgo de ingenio") ${ }^{14}$. También en este caso podemos, pues, dar por descontados los tres principios que según un agudo crítico literario norteamericano, Lee Patterson, permiten al crítico textual afanarse felizmente en la reconstrucción:

The editorial process is enabled by three assumptions: that there is an original; that the original is qualitatively different from an unoriginality in which it is submerged [entiéndase: porque está libre de las lecciones incorrectas presentes en las varias copias que han sobrevivido]; and that it has a meaning that is enacted in the language at every point ${ }^{15}$.

Un último apunte preliminar. Rico tiene razón al observar que "transmisores de una competencia lingüística y cultural equiparable a la de los autores" pueden corregir por aquí y por allá de un modo sensato el texto a su disposición. Pero, como él mismo reconoce, todas las ediciones antiguas del Lazarillo que han llegado hasta nosotros fueron hechas "al trote", más o menos precipitadamente. Por lo cual, si frente a pocos errores y no

14 Francisco Rico, "Introducción" a Lázaro de Tormes, Lazarillo de Tormes, 2011, p. 97.

15 Lee Patterson, "The Logic of Textual Criticism", en Negotiating the Past. The Historical Understanding of Medieval Literature, Madison, The University of Wisconsin Press, 1987, p. 111. 
demasiado difíciles de corregir la estemática neolachmanniana se queda sin armas, dado que todas las hipótesis (error poligenético, corrección poligenética...) son admisibles, una serie suficientemente amplia de errores que no resultan significativos, si examinados uno a uno, pero que tienen la misma distribución que los errores significativos, no puede no querer decir que la orientación sugerida por los errores propiamente dichos es - y nos contentamos con esta etiqueta - el menos improbable. Y continúa siendo así, claro está, también delante de eventuales, esporádicas excepciones, especialmente si atañen a acuerdos explicables por poligénesis, incluida la consabida iniciativa de copistas o tipógrafos particularmente sagaces $^{16}$.

4. LAS ELECCIONES «VARIANTE POR VARIANTE» Y MI ESTEMA DEL LAZARILLO

Contra las reglas mediante las cuales se fabrican también hoy día las novelas policíacas mediocres, anticipo, para comodidad del lector, el estema al que he llegado reexaminando las variantes de los principales testimonios a la luz de la bibliografía más reciente, y que intentaré justificar en los siguientes párrafos:

$1552-1553$

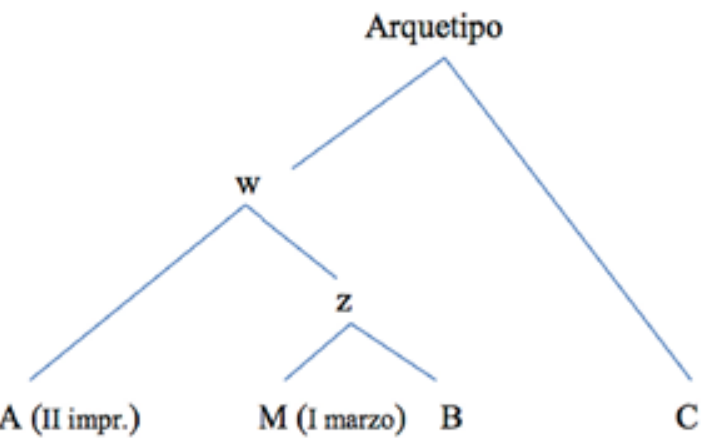

16 Sobre los errores que cabe estimar como poligenéticos, o mejor, como sospechosos de poligénesis, véase Paolo Trovato, Everything You Always Wanted to Know about Lachmann's Method, pp. 116-117; sobre los confirmatory readings, ibidem, pp. 110-115. 
Incluso antes de declarar por qué he llegado a un estema con esta forma (atesorando, nobleza obliga, aquellos que me han parecido los datos y argumentos más persuasivos de Ruffinatto, Blecua y otros estudiosos, Rico incluido), quisiera brevememente pasar revista al catálogo, casi completo, de las variantes que figuran en la rama de la tradición $(w)$ que Rico ha privilegiado en su edición: fundándose casi exclusivamente —a la manera de los grandes humanistas - en su iudicium de filólogo, eligiendo con la máxima libertad ora de esta, ora de aquella edicioncita quinientista (y en un caso hasta de la desacreditada impresión de Amberes 1555). He aquí sus palabras:

Para establecer el mío, no he echado mano de ningún «texto de base» ni me he valido de ningún estema. Todos los elementos de juicio señalan que la princeps estaba tan cercana y las primeras ediciones conservadas se hicieron tan al trote y en talleres tan semejantes, que cualquiera de las unas puede traer lecciones de la otra, cometer los mismos deslices que las restantes y separarse de su modelo con las mismas enmiendas [...]. Así las cosas, para ascender a la princeps (como para seguirla o no), he procedido variante por variante, valorando en especial cuál o cuáles de ellas (o qué otras) podían haber dado origen a las demás, se elucidaban por la ratio typographica o se ajustaban mejor a los usos lingüísticos y literarios de la obra y de la época [...]. El resultado es un texto ecléctico pero por ello mismo con más probabilidades de acercarse al original que el forzado por un estema o un único testimonio ${ }^{17}$.

Con fines didácticos (habida cuenta de que estoy persuadido de que, cuando resulta aplicable, el método neolachmanniano es preferible incluso al refinado eclecticismo de un estudioso de la talla de Rico), añadiré, cuando sea necesario, a la desnuda lista de errores y variantes algún comentario puntual. Por supuesto, mis observaciones no se escudarán en las inferencias que podrían extraerse, en términos de lógica lachmanniana, de mi estema (siempre y cuando, se entiende, que sea mejor, es decir, más respetuoso con los datos y más económico, que los estemas de Moll, Cañas, Carrasco, Ruffinatto y los dos propuestos por Blecua, respectiva-

17 Francisco Rico, "Introducción y notas" a Lázaro de Tormes, Lazarillo de Tormes, 2011, pp. 208-209. Las cursivas son mías. 
mente en 1972 y 2003$)^{18}$.

En el intento de demostrar que las variantes que no proceden de C, aceptadas para el texto por Rico (aquí abajo, en la columna de la izquierda) son cuando menos adiáforas, me serviré, en suma, de sus mismas armas (la ratio typographica, los «usos lingüísticos y literarios de la obra y de la época» y similares). Para evidenciar mejor la validez de ciertas variantes rechazadas, indicaré además con la sigla Ble las elecciones de la edición de Blecua 1972, que (conforme al estema Cavaliere-Rico, B / AC, remozado con nuevos argumentos por Blecua) tiende a privilegiar, también cuando son aisladas, las lecciones de B. Dado que, desafortunadamente, ningún editor crítico ha procedido hasta ahora a introducir en el Lazarillo una numeración de los párrafos (siempre oportuna con textos en prosa), aquí y en lo sucesivo remitiré a la página y a la línea de la edición Rico 2011.

Tabla 1. Variantes que no proceden de C recogidas en el texto de la edición Rico 2011 (excepción hecha de los errores de arquetipo y de los seguros errores comunes de $M B$ )

\begin{tabular}{|l|l}
\hline 4.11 le loaba MBA Ble & lo loaba $\mathrm{C}$ \\
\hline 10.22 duró MBA Ble & turó C
\end{tabular}

Como ya se ha indicado, para un neolachmanniano la mejor solución por lo que se refiere a los aspectos fonomorfológicos sería la de atenerse siempre al mismo testimonio, tanto más cuanto en varios lugares y testimonios hay acuerdo ora en turar, ora en durar: 16 Mas turóme poco, 31 le turaba toda la semana, 36 cuán poco turan los placeres., contra 34 me durase mucho, 58 no durase, 68 no me duraron ocho días, ni yo pude [...] durar más. En 31.6 el mismo Rico elige con MB turaba en lugar de duraba de AC.

14.8 traía $\mathrm{MB}$

14.9 decía que Galeno MBA Ble traían AC Ble

decía Galeno C

18 Como es sabido, en condiciones normales, una vez demostrado de modo incontrovertible, por ejemplo, que A, por una parte, y los colaterales $\mathrm{B}$ y C, por la otra, descienden del arquetipo, se puede deducir que eventuales lecciones aparentemente buenas de $\mathrm{C}$ contra $\mathrm{AB}$ son meras conjeturas y no lecciones conservadas (ley de la mayoría). Pero en el caso aquí sometido a discusión, máximamente controvertido, parece oportuno aplazar deducciones de este tenor para algo más tarde. 
Si se escoge la lección, menos perspicua, de C, tanto la elipsis de que cuanto la lectura de decía como incidental ("en caso de medicina — decía- Galeno no supo la mitad que él...") consentirían evitar la repetición de que a breve distancia (“en caso de medicina, decía que Galeno no supo la mitad que él..."). Remito, a título puramente ejemplificador, a algunos ejemplos de elipsis en los textos del CORDE compuestos entre $1400 \mathrm{y}$ 1600 , que evidencio con el signo ø: "yo deseo ø se le haga alguna releuada merced", "deseo ø se tomen pocas casas en Andalucía", "El de Job deseo ø se ynprima luego", "perpetuando el llanto, que desseava ø fuesse el último de mis llantos". En el Lazarillo se hallan ejemplos de elipsis de que tanto con valor declarativo como relativo: por ejemplo, 5 "Suplico a Vuestra Merced ø reciba el pobre servicio", "pues Vuestra Merced escribe $\emptyset$ se le escriba”; 10 "diciéndole [...] que ella confiaba en Dios ø no saldría peor hombre que mi padre, y que le rogaba ø me tratase bien"; 33 "Vino el mísero de mi amo, y quiso Dios ø no miró en la oblada" (si bien en 36, “quiso Dios que aun en esto me fue bien”); 38 "según la clavazón y tachuelas ø sobre sí tenía”.

\subsection{2 cojed A}

cosed MBC Ble

Cosed, en el arquetipo, parecería tener poco sentido en su relación con hierba, y presupone de forma verosímil un coced en el original. Ruffinatto y Rico leen, con Velasco, coged. Como resume Blecua en sus ediciones de 1972 y 2011, p. 178: "Si se edita cosed debe entenderse por coced; si por coged, debe corregirse la errata 'cosed' e imprimir coged'. Pero es cierto que el cambio de sibilante no basta para reagrupar MBC y tampoco la oposición $\mathrm{MBC} / \mathrm{A}$, fundada apenas en un grafema, que es de naturaleza poligenética.

\section{9-10 a hacerle menos A}

17.9 sotil MBA Ble hacerle menos MBC Ble

sutil C

Se trata, como en 10.22 y en otros casos parejos, de una típica oposición formal.

\begin{tabular}{|c|c|}
\hline 18.22 Y aunque MBA Ble & Aunque $\mathrm{C}$ \\
\hline 19.1 Pensaréis MBA Ble & Pensáis C \\
\hline 22.3-4 por no lo haber MBA Ble & por no haber $\mathrm{C}$ \\
\hline 22.15 se le escondía MBA Ble & se le ascondía C \\
\hline
\end{tabular}

En rigor, solo se puede observar que asconder es más arcaico, menos banal si se quiere.

$\begin{array}{ll}22.18 \text { abríame la boca MBA Ble } & \text { abriome la boca C } \\ 23.19 \text { donaire recontaba B Ble } & \text { donaire contaba MAC }\end{array}$

Para Blecua ("La edición del Lazarillo de Medina del Campo", p. 293) y Rico 2011, p. 225a, la haplografía de MAC a partir de la lección de B es más probable que lo contrario, o sea, una ditografía de B, pero se trata, en ambos casos, de incidentes frecuentísimos en la imprenta; además, la duplicación de la sílaba re se da en B precisamente en la zona crítica del cambio de página: donaire es la última palabra de c.B3r; recontaba la primera de cB3v. En el resto del Lazarillo, pues, se registra siempre contar, nunca recontar ("Huelgo de contar a V. M. estas niñerías"; “contando sus cosas, V. M. sepa que...”; "burlas endiabladas, de las cuales contaré algunas", etcétera.). Nos hallamos, pues, y no representa ninguna sorpresa, frente a "suposiciones inseguras" que no impiden diseñar, como ha escrito Rico, "cualquier estema”, ni construir cualquier "texto ecléctico".

24.10 si un hombre en el mundo B Ble si hombre en el mundo MAC 
La defensa de la lección de B por parte de Rico 2011, 225b ("El Lazarillo no emplea hombre como impersonal...") no termina de convencerme. Otro caso de hombre sin artículo se documenta, aquí mismo, en 64.7. Y sobre todo, hombre en el mundo, sin artículo, es un fósil de la lengua literaria que goza de larga presencia en la tradición española. En el nunca suficientemente alabado CORDE se registran decenas de ocurrencias de no ay (havia, havria, hubiera...) hombre en el mundo..., no fuera hombre en el mundo..., cometer más males que hombre en el mundo, que podemos confrontar con los modismos italianos (también boccaccianos) persona del mondo o uomo al mondo. En el mismo Lazarillo se lee en 63 "ni sufriré a hombre del mundo, del rey abajo"; y en 15 (también si, como se procurará demostrar, se trata de una innovación singularis di B) "era con tan gran vigilancia y tanto por contadero, que no bastaba hombre en todo el mundo hacerle menos una migaja”. Y el mismo giro sintáctico se muestra activo también en 73 "no había mula falsa en el mundo que...”.

25.8-9 de bajo de los portales MBA Ble de bajo los p. C, cfr. 40.8

Plausiblemente Rico escoge también en 40.8, esta vez con MBC frente a A, de bajo de.

26.1 Olé, olé MBA Ble

Olé C

31.6 turaba MB Ble

duraba AC

Véase, sin embargo, 10.22, donde Rico prefiere, con MBA, duró (un breve comentario aquí arriba).

31.10 cofradías MB Ble confradías C, cofadrías A

31.12 dije MB Ble deje $\mathrm{A}$, dice $\mathrm{C}$

31.20 aqueste $B$ este MAC Ble

32.2 sería casi seis meses B Ble serían casi seis meses MAC

32.24 llegose acaso B Ble llegose a caso MAC

33.17 allegar B Ble llegar MAC

38.7 era yo B Ble yo era MAC

38.12 ca en pocos días B Ble y en pocos días MAC

41.4 me descargó MBA Ble me descarga $\mathrm{C}$

El paso repentino del perfecto al presente, sobre todo (como en este caso) con verbos de gran peso semántico, es un rasgo típico del stream of consciousness de Lázaro. Véase por ejemplo 50.18, o 52.15-16, o 54.1-2. Descarga parece, en suma, digno de atenta consideración.

\begin{tabular}{|l|l}
\hline 41.4-5 un tan gran golpe B Ble & tan gran golpe MAC \\
\hline $\begin{array}{l}\text { 42.4 comiénzanme a quitar BA Ble } \\
\text { 43.17 Pasábamos MBA Ble }\end{array}$ & Pasamónzanme quitar AC \\
\hline 43.21 no lo vee MBA Ble & no le vee C \\
\hline
\end{tabular}

A diferencia de 4.11 (donde lee le loaba con MBA), Rico prefiere aquí y en 72-6 (yo lo perdono) para el acusativo la forma pronominal 'etimológica', atestiguada en MBA y MB, respectivamente. Pero los testimonios coinciden a menudo en la forma leista: por ejemplo, "mi amo les fue a la mano y mandó a todos que [...] no le estorbasen, mas que le dejasen decir todo lo que quisiese", "otros le tiraban por las piernas", "yo le he usado" etcétera. 


\begin{tabular}{|c|c|}
\hline 44.3 A buen MBA Ble & Y a buen $\mathrm{C}$ \\
\hline 44.12 parece $\mathrm{B}$ Ble & parecía MAC \\
\hline 47.5 que yo había MBA Ble & que había C \\
\hline 49.20 venido el día MBA Ble & veniendo el día $\mathrm{C}$ \\
\hline
\end{tabular}

Como señala Blecua en sus ediciones de 1972 y 2011, p. 181, en el nivel paleográfico "es más fácil el paso de un veniédo a un venido quel al contrario". Ademas, con los datos del CORDE a mano, la formulación de C es atestiguada, a lo largo del par de centurias que median entre 1400 y 1600, solo en tres ocasiones; la de MBA cuenta con 107 casos documentados, o sea, es 30 veces más frecuente. De hecho, veniendo el día, es decir, 'al comienzo del nuevo día', o bien 'en cuanto fue posible', parece adaptarse mejor a los futuros que inmediatamente le siguen y sobre todo a las expectativas del hambriento Lázaro: "Pasemos como podamos y mañana, veniendo el día, Dios hará merced; porque yo, por estar solo, no estoy proveído, antes he comido estos días por allá fuera. Mas agora hacerlo hemos de otra manera”.

\begin{tabular}{|l|l}
\hline 50.3 más y más sano MBA Ble & más sano $\mathrm{C}$ \\
\hline 50.19 jubón y sayo y capa B Ble & jubón, sayo y capa MAC \\
\hline 52.11 no sufrirán MB Ble & no sufrirían AC \\
\hline
\end{tabular}

Contra la lectura del par de ediciones de Blecua (reafirmada en su caso en el artículo "La edición del Lazarillo de Medina del Campo”, 2003) y de la última de Rico 2011, la lección de AC (“;Oh Señor, y cuántos de aquéstos debéis vos tener por el mundo derramados, que padecen por la negra que llaman honra lo que por Vós no sufririan!"), que también yo considero preferible, es la editada por Ruffinatto.

53.12-13 comiendo certos tronchos de berzas con los las $\mathrm{C}$ quales me desayuné MBA Ble

En C el pronombre concuerda con berzas y no con tronchos.

54.17 Como entro, vínose B como entré, vínose MAC Ble

54.26 más vale pedillo per Dios que no hurtallo hurtalle $\mathrm{C}$ MBA Ble

Sobre las numerosas formas leístas del arquetipo, véase lo dicho supra a propósito de 43.21.

55.24 como comencé a comer y él MBA Ble comer[,] él C

55.27 Dígote $[\ldots]$ que nadie te lo verà hacer que $\mathrm{A}$ vea $\mathrm{B}$, vee $\mathrm{MC}$ Ble

La subordinada se vincula con que tienes ("Dígote [...] que tienes en comer la mejor gracia y que nadie te lo vee hacer que no le pongas gana [sc. de comer]").

56.10 y asentóseme MBA Ble asentóseme C

58.15 de la laceria que les traía, me daban... MB Ble ellas tenían A, les traían C 
Como Blecua (que ratifica su elección en el artículo "La edición del Lazarillo de Medina del Campo"), Rico se decanta por la lección de MB y propone dos significados alternativos, ambos muy elaborados ('la miseria con que me presentava', 'la pena que les daba'). Pero, como argumento en la tabla 7, la elíptica lección de C armoniza mejor con una acepción semántica de laceria típica del Lazarillo.

59.7 deseo que se acabe B Ble

deseo se acabe MAC

La elección de Rico 2011, p. 230b, es aquí analógica (“Lo normal en el Lazarillo es desear que”). Pero, como se ha advertido ya supra (varios ejemplos con desear en 14.9), la elipsis de que no resulta nada improbable.

59.11 con el cual él vino MBA Ble

con el cual vino $\mathrm{C}$

Rico prefiere editar el pronombre: "un día, no sé por cual dicha o ventura, en el pobre poder de mi amo entró un real, con el cual él vino a casa”. Pero por lo regular, en las subordinadas con relativos oblicuos, el anónimo (y también en un caso el interpolador de A, cuyo escolio indico entre llaves) omite el sujeto pronominal, deducible a partir del verbo: 77 "fue un oficio real, viendo que no hay nadie que medre sino los que le tienen; en el cual el día de hoy vivo"; 77 "tengo cargo de [...] acompańar los que padecen persecuciones por justicia y declarar a voces sus delitos: pregonero, hablando en buen romance, \{en el cual oficio un día [...] conocí y cai en la cuenta de la sentencia"; 67 "el alguacil y el escribano piden al hombre y a la mujer sus derechos, sobre lo cual tuvieron gran contienda y ruido"; 69 "diré uno muy sotil y donoso, con el cual probaré bien su suficiencia"; 72-73 "le trabaron de los brazos, con los cuales daba fuertes puńadas a los que cerca dél estaban"; 74 "comienza una oración no menos larga que devota, con la cual hizo llorar a toda la gente"; 75 "estuve con este mi quinto amo cerca de cuatro meses, en los cuales pasé también hartas fatigas"; 76 "ahorré para me vestir muy honradamente de la ropa vieja, de la cual compré un jubón de fustán viejo".

60.5 venían $\mathrm{MB}$ Ble

venía $\mathrm{AC}$

Como procuro argumentar en la tabla 7, la lección rechazada ("venía luego par del lecho una que debía ser su mujer del difunto [...] y con ella otras muchas mujeres, la qual iba llorando a grandes voces") parece la única aceptable.

60.17 venga a ayudar $\mathrm{A}$

venga ayudar $\mathrm{MBC}$ Ble

61.31 no errábades en no quitárselo primero...? MB Om. AC Ruff

Ble $\mathrm{Ri}$

Si la frase se entiende como interrogativa, la omisión de AC podría ser poligenética (se elimina el no a muy corta distancia de otro no), o bien remitir al arquetipo, sobre cuya existencia todos los estudiosos recientes concuerdan (véase, aquí, la tabla 2), y haber sido subsanada por el antígrafo de MB. Pero, también a la luz de la puntuación bastante exacta de las ediciones antiguas, en las cuales el signo interrogativo falta, es posible leer la frase como afirmativa (tal como lo hiciera ya Ruffinatto) y entonces "no errábades en quitárselo primero" tendría sentido. Por otra parte, el escudero responde con un doble sí ("Sí es, y sí tiene”) a la premisa hipotética de Lázaro: "Si él era lo que decís y tenía más que vós".

$62.22^{19}$ maña MB Ble

manera AC

Adiáfora.

63.6 nunca más le quise sufrir, ni sufriría ni sufriré sufría C

MBA Ble

19 Y no 68.22, como reza en Lázaro de Tormes, Lazarillo de Tormes, ed. Francisco Rico, 2011, p. 231. 
La lección de $\mathrm{C}$ no debe considerarse errónea: el escudero no ha podido sufrir (en la fase actual de su vida), no sufría en el pasado, no sufrirá en el futuro. Sufriría parece forma de armonización, que se explicará obviamente por repetición o por anticipación del tema sufrir-.

63.13 docientas mil maravedís MA

docientas veces mil maravedís B Ble, docientos mil maravedís C

Entre 1400 y 1600 las variantes de MA y C son sustancialmente adiáforas.

63.19 los sacarán de su paso MBA Ble

sacará C

Para Rico 2011, p. 231, se trata de una "concordancia ad sensum normalizada por C", pero la frase ("es gente tan limitada, que no los sacará de su paso todo el mundo") figura en el discurso directo del escudero, que se expresa por lo general en un registro bastante moderado. La hipótesis de una concordancia "de corto alcance”, según era moneda común entre copistas y tipógrafos (aquí detrás del plural los y del verbo que sigue a continuación), parece más económica.

64.1-2 servir con éstos MB Ble

64.4 y la más y la más ciertas MB servir a éstos ACBle

y lo más más cierto A, y la más ciertas $\mathrm{C}$

Contra Ble 291 y Rico, creo que P* leyó como C: Y la más veces son los pagamentos a largos plazos, y la más ciertas comido per servido. La duplicación de y la más se explicará por ditografía, $\mathrm{y}$, a la luz de la evidencia de que el sintagma repetido se encuentra en $\mathrm{M}$ en la zona crítica del final de renglón, la ratio typographica sugiere que se encontraría en la misma posición también en $w$ (lo que explica el error de los colaterales $\mathrm{MB}$ y el error crítico de A, que procura, como de costumbre, corregir aquello que no le convence).

64.6 sois librado B

64.7 Ya cuando asienta un hombre B Ble

64.18 si riñese con alguno B Ble sois librados MAC Ble

Ya cuando asienta hombre MAC

rieñese MAC

65.13 de dos en dos meses le alcanzaron lo que él en dos MAC un año no alcanzara B Ble

Según Blecua ("La edición del Lazarillo de Medina del Campo”, pp. 292-293) y Rico 2011, p. 231b, a partir de cuya edición cito, la variante de MAC es "obvia omisión per homoiotéleuto". Sin embargo, la lección de la mayoría sigue un extendido modelo literario, atestiguado en el propio Lazarillo ("ganaba más en un mes que cien ciegos en un año"). Espigo en las primeras pantallas del CORDE (búsqueda: en un año) otros ejemplos coevos: "tierra holgada abundosamente frutifica y da más en un año que la muy cansada en tres", "sabe mucho más en un año que un canonista en tres", "los maestros a los discípulos más con buenos exemplos en un día que con muchas lectiones les aprovecha en un año", “¿Qué crueldad mayor de enemigos que den más a un loco en un día que a sus criados en un año", "más deprenden algunas a chocarrear en una hora que a labrar en un año", "mas sabras en un dia que te recojas en tu camara leyendo que en un ańo que gastes por el mundo io", "tú pides que se concluya en un día lo que en un año sería harto". Además, la dilatación de B se sitúa en la misma línea de muchas otras (66.19 muchas veces $\rightarrow$ muchas e infinitas veces, 66.22 di lo que sabes $\rightarrow$ di todo lo que sabes, etcétera), ya encuadradas por Moll en la frecuente tendencia de B a amplificar, según fuera necesario, el texto por razones tipográficas.

65.22 les responden $\mathrm{A}$

66.11 les respondí A le responden $\mathrm{MBC}$ Ble

le respondí $\mathrm{MBC}$ Ble 
67.10 vuesas mercedes MA

67.21 aunque no iba B Ble

68.4-5 negocios seglares y visitar MBA Ble vuestras mercedes BC Ble

y aunque no iba $\mathrm{MBC}$

visitas $\mathrm{C}$

En el lugar paralelo de Diego Hurtado de Mendoza citado por Rico 2011, visitar encabeza una serie de infinitivos ("no visitar, ni recibir dones..., no vestir, no gastar suntuosamente"); en C, en cambio, visitas está coordinado con el sustantivo negocios. No pretendo sostener que la variante con visitar sea inadmisible, por más que ditologías del tipo negocios y visitas están mejor aclimatadas en la tradición literaria de la época. Gracias al CORDE, es posible sumar al ejemplo del Guzmán señalado por Ruffinatto ad loc., otros testimonios del binomio: por ejemplo, "visitas o negocios" en las anónimas Relaciones histórico-geográficas-estadísticas de los pueblos de España, 1575-1580; "pleitos, negocios, visitas”, en Fray Alonso de Cabrera, a. 1598; y la variante "visitas y ocupaciones”, en Santa Teresa de Jesús, 1580.

70.22 y así MA Ri

y así se fue B, así C

Salvo error, en el Lazarillo no hay constancia de casos de para-hipotaxis introducidos por y así después de prótasis amplia, típicos del Quijote (Rico), donde los arcaísmos poseen a menudo valor paródico.

70.17 que predicaba que eran falsas B Ble que predicaba eran falsas MAC

El contexto es: "el alguacil dijo a mi amo que era falsario y las bulas que predicaba que eran falsas".

70 18-19 no bastaban a ponellos MBA Ble

70.19 el aguacil B Ble ponellos C

al aguacil MAC

En la frase: "acordaron de llevar $e$ alguacil de la posada a otra parte".

70.27 tras B Ble

71.8 quisiéredes B Ble

71.20 el aguacil B Ble atrás MAC

quisierdes MAC

al aguacil MAC

"Algunos hombres honrados [...] se quisieron levantar y echar $e l$ alguacil fuera de la iglesia".

72.6 yo lo perdono MB Ble

72.9-10 y dando crédito MBA

73.14 podría MBA Ble

74.22 recibe mucha pena $\mathrm{Si}(=$ Amberes 1555$)$ yo le perdono $\mathrm{AC}$

dando crédito C Ble

podía $\mathrm{C}$

recibía mucha pena MAC Ruff, reciba mucha pena B Ble

La variante de Si aparece registrada ya en el aparato de Ruffinatto, pero lo cierto es que la lección de C (para ser exactos, de MAC) me parece inatacable: "el pecador [...] confesó haber dicho aquello por la boca y mandamiento del demonio, lo uno por hacer a él [sc. al comisario] daño y vengarse del enojo, lo otro y más principal, porque el demonio recibía mucha pena del bien que allí se hiciera en tomar la bula" (se hiciera, cuando está subordinada a una oración principal con verbos en pasado, adquiere, como en italiano antiguo, el valor de "se habría hecho").

75.14 de éste $\mathrm{A}$

77.7 el dia de hoy vivo MBA Ble desto MBC Ble

el dia de hoy yo vivo $\mathrm{C}$ 
78.2-3 mi señor el arcipreste MA

78.8 nunca faltaron ni faltarán MBA Ble

A juzgar por la en general fluida copia verborum del anónimo (3 nunca oidas ni vistas, 60 nunca comen ni beben), se trataría de un error separativo de C.

78.9 diciendo no sé qué y sí sé qué, de que veen MBA Ble om. C

Otro error sin duda de C, explicable por saut du même au même del segundo al tercer que.

79.9-10 echar maldiciones MBA Ble

echar mil maldiciones $\mathrm{C}$

Como se ha visto, se trata en la mayor parte de los casos de lecciones adiáforas, cuyo alcance semántico y estilístico es casi irrelevante (le loaba / lo loaba, duró / turó, a hacerle menos / hacerle menos, sotil / sutil...), o, todo lo más, de leves erratas corregibles de inmediato. Razón por la cual, si el estema invita a decantarse, en los casos dudosos, por las lecciones de un determinado testimonio, toda vez que representa, pongamos por caso, una rama entera de la tradición ( $\mathrm{C}$, como he propuesto, pero también $\mathrm{M} \mathrm{o} \mathrm{B}$ ), el texto del Lazarillo ("obra sin apenas problemas textuales prácticos", en correcto diagnóstico de Blecua) no cambiaría sino marginalmente. Además, si no me engaño, al menos alguna de las elecciones de Rico a favor de MBA (en mi estema: $w$ ), o de una de las tres ediciones del XVI que yo estimo que derivan de $w$, quedaría refutada de acuerdo con las consideraciones de tipo estilístico o semántico que acabo de anticipar. Pero, para evitar equívocos, debo señalar que, en la abrumadora mayoría de los casos, la lección de $\mathrm{C}$ es la elegida también en la edición Rico, porque, en los casos que él ha considerado dudosos, que son justamente muchísimos, el estudioso se "ha resignado a leer con la mayoría de las ediciones" ${ }^{20}$.

\section{El ARQuetipo}

Como no han dudado en afirmar todos los estudiosos que han venido indagando sobre esta genealogía, las cuatro ediciones más antiguas remiten a un arquetipo, identificado con la perdida princeps $\mathrm{P}^{*}$, o quizá mejor (dado el

20 Francisco Rico, "Introducción” a Lázaro de Tormes, Lazarillo de Tormes, 2011, p. 209. 
buen número de errores que la caracterizan) con una reedición apresurada y casi inmediata de la princeps, fruto de la rápida venta de la primera tirada y de la creciente demanda por parte del público ${ }^{21}$. Añado a la sigla Ble, que remite como he dicho a la edición Blecua 1972, las siglas Ruff y Ri, que aluden, respectivamente, a los textos de Ruffinatto 2000 y Rico 2011. La sigla Ve indica la edición de Madrid 1573, “corregida y emendada” por el polígrafo y “secretario del Consejo de las Indias” Juan López de Velasco ${ }^{22}$.

\section{Tabla 2. Verosimiles errores de arquetipo o atribuibles al arquetipo (en tanto que presentes en ambas ramas).}

algunas noches $\mathrm{Ri}$

La propuesta de corrección veces > noches se avanza ya en el aparato de Blecua 1972 (2011), p. 178.

8.5 a cal(l)entar MBAC Ble Ri a acallar Ve Ruff

El primer editor moderno que hizo suya la enmienda de Velasco es Carrasco, citado por Ruffinatto 2000, p. 111. Acallar es un término técnico del cuidado de los niños: hizo acallar los mochachos; arrullar y acallar el Niño; halagar y acallar al niño, tomándolo en sus brazos (por lo general, los ejemplos están sacados del corpus $C O R D E$ ). Puedo añadir que el del arquetipo es un error de repetición, fruto de la cláusula del periodo precedente: “... nos calentábamos”.

14.19 me mataba a mí de hambre, y asi (assí) no me a sí no se demediaba (remediaba Ve Ruff) Ve Ruff Ri demediaba (remediaba C) de lo necesario MBAC Ble

Una vez reconocida la banalización separativa de C (donde remediaba anticipa la presencia de un contiguo remediar: "si [...] no me supiera remediar"), podemos centrarnos en el error del arquetipo, es decir, en la repetición de me. Ve y Ruff corrigen me como se, pero conservan remediaba de C. Por lo que respecta al significado del pasaje así corregido, de acuerdo con los atributos del personaje (“jamás tan avariento ni mezquino hombre no vi”, "De la taberna nunca le traje una blanca de vino, mas aquel poco que de la ofrenda había metido en su arcaz compasaba de tal forma que le turaba toda la semana"), Rico explica: "no llegaba a comer la mitad de lo que necesitaba".

21 Sobre la noción de «arquetipo» y acerca del oscurecimiento del «arquetipo» por mor de los copistas e impresores, véase Paolo Trovato, "Archetipo, stemma codicum, albero reale", Filologia italiana, 2 (2005), pp. 9-18; y sobre todo, del mismo autor, Everything You Always Wanted To Know about Lachmann's Method, pp. 138-155.

22 Útiles indicaciones sobre Velasco en Pablo Jauralde Pou, "Sin que de mi nombre quede otra memoria (Diego Hurtado de Mendoza y el Lazarillo de Tormes)", manuscrt.cao. Revista de Manuscritos Literarios e Investigación, 8 (2010), cap. II, Francisco Rico, "Introducción" a Lázaro de Tormes, Lazarillo de Tormes, 2011, pp. 203-204, que sería oportuno integrar, en lo relativo a su práctica de editor, con Aldo Ruffinatto, Las dos caras del "Lazarillo", pp. 125 ss. (del que procede la cita). 
La necesidad de la enmienda de Rico, ya presente en las dos ediciones tardorrenacentistas recién citadas (registradas en los aparatos de Ruffinatto 2000, p. 135, nota 35, y Rico 2011, p. 223b), está fuera de discusión porque sustituye una fórmula tosca y aproximativa por una metáfora inspirada en el arte militar que asoma en las cortes de la Europa renacentista ("si con mi sotileza [...] no me supiera remediar, [...] me finara de hambre. Mas, con todo su saber y viso, le contraminava de tal suerte, que [...] me cabía lo más y mejor”). Varios testimonios españoles de este contraminar metafórico (cotejable con los italianos del GDLI, s.v. controminare: Bandello, Caro, Salviati... $)^{23}$, se registran en el CORDE: "como los buenos tienen obligación de minar el mal, no menos los malos tienen osadía para contraminar y derrocar el bien" (Fray Antonio de Guevara, Libro áureo de Marco Aurelio, 1528); "Había muchos leales servidores de Su Majestad que contraminaban los designios y propósitos de Gonzalo" (Pedro Gutiérrez de Santa Clara, Quinquenarios o Historia de las guerras civiles del Perú, 1549-1603); etcétera.

\subsection{6-17 habiéndome puesto dentro MBCA Ble Ri habiéndome puesto dentera Ve Ruff}

Si admitimos con Patterson que el significado de obras maestras como el Lazarillo "is enacted in the language at every point", la conjetura alternativa de Rico ("habiéndoseme puesto dentro") se derrumba frente a la recuperación, sugerida por la edición de Velasco, de una densa metáfora debidamente glosada en el Diccionario de Autoridades ("Dar dentera. Phrase vulgar metaphorica con que se explica, que el ver alguna cosa cáusa deseo, apetito, o envídia”). No obstante la difidencia de Blecua ("La edición del Lazarillo de Medina del Campo", p. 296), quien escribió: "habría que documentar la construcción poner dentera", también la variante empleada en el Lazarillo se corresponde con varios textos de aquella época: "Pónesme tanta dentera, tú por vna parte y Felides por otra, que..." (Gaspar Gómez de Toledo, Tercera parte de la tragicomedia de Celestina, 1536); "para ponerles más envidia y dentera" (Juan de Arce de Otárola, Coloquios de Palatino y Pinciano, c. 1550); "poniéndoos a vos dentera y más gana de encontrar...” (Sebastián de Horozco, Cancionero, c. 1540-1579). Huelga añadir que, si no depende de la mera ignorancia de un cajista, la banalización del arquetipo se explicará como una abreviatura mal resuelta.

\subsection{1 a la gulilla (golilla A) MBCA Ble Ri al galillo Ve Ruff}

Para Rico se trata de una variante adiáfora, pero gal(l)illo es un preciso término técnico, y por ello difficilior: como consta, verbigracia, en los siguientes lugares: "Delos males del gallillo e dela garganta" (Alfonso Chirino, Menor daño de la medicina. Escorial, b.IV.34, a 1429); "los quales nocumentos o empescimientos reputo grandes Auenzoar de esquinancia quando era cortada la vulua o galillo en el tratado. iiij." (Traducción del Tratado de cirugía de Guido de Cauliaco. Madrid, BNE I196, 1493); "Para una enfermedad que se haze baxo la lengua, que dizen canpanilla. Algunas vezes, por grande descendimiento de flema, que desçiende a la garganta, cuelgase so la luenga $[$ sic $]$ una enfermedat qu'es en guisa de canpanilla, que semeja que quiere a ome afogar e a las mugeres. E llaman a esta enfermedad el gallillo o la ranilla. Mas, para esta enfermedad guareçer, mandala fazer gargarismos ..." (Fernando de Córdoba, Suma de la flor de cirugía, c. 1500); "abriéndole el pico, le untan con aquella miel el gallillo" (Fadrique de Zúńiga y Sotomayor, Libro de cetrería de caza de azor, 1565); "Sirve también el pulmón para la voz, porque saliendo el aire que él despide de sí con algún ímpetu, y tocando en el galillo o campanilla que tenemos a la entrada dél, se forma la voz" (Fray Luis de Granada, Introducción del símbolo de la fe, 1583). Otros datos en Aldo Ruffinato, Las dos caras del "Lazarillo», p. 111.

23 Grande dizionario della lingua italiana, fundado por Salvatore Battaglia, Torino, Utet, 1961-2002, 21 vols., Supplemento 2004 e Supplemento 2009, ed. Edoardo Sanguineti, Torino, Utet, 2004-2009, 2 vols. 
24.25 el día también llovía, y andaba rezando debajo mojábamos Ve Ri de unos portales que en aquel pueblo había, donde no nos mojamos MBAC Ble Ruff

A diferencia de Caso González y Ruffinato, que leen mojamos como un imperfecto, Rico 2011, p. 225b, anota: "Frente a los regulares -ábamos, creo [...] que se trata de un error común".

33.5 hay algunas MBC Ruff

hay alguna $\mathrm{A}$ Ve Ble Ri

Ruffinatto atribuye la lección algunas también a A, pero la edición facsimilar de 1959 lee alguna, como se indica en los aparatos de Blecua y Rico. Se trata, de cualquier modo, de una fácil conjetura regularizadora en el haber del corrector de A: "Por vuestra vida, veáis si en esas [llaves] que traéis hay alguna que haga".

37.18 deyuso MBAC Ble

desuso Ve Ruff Ri

Se trata, como advierte Rico 2011, p. 227b, de un clásico error de sustitución de un término por su antónimo.

51.17-18 Quien no lo conosciera pensaba ser muy al conde Claros cercano pariente al Conde de Arcos (del conde Alarcos

A) o a lo menos camarero que le daba de vestir MBAC

Ble Ruff Ri

Con independencia de la cautela de los sucesivos editores, la necesidad de esta enmienda (de Alfred MorelFatio) la argumentó impecablemente Menéndez Pidal allá por 1899 (Antología de prosistas españoles. I, Madrid, CSIC, 1992, p. 81), quien anotaba: "Las ediciones dicen Conde Alarcos o Conde de Arcos, héroe de un romance [sc. Retraida está la infanta] en que para nada se habla de lujo y galas. Hay que corregir Conde Claros, protagonista de otro romance que [...] describe largamente cómo el Conde se viste ayudado por el camarero que recuerda Lazarillo: «[...] Conde Claros con amores / no podía reposar [...]. / Cuando vino la mańana [...] / voces da por el palacio / y empezara de llamar: / "levantá, mi camarero: / dame vestir y calzar" "”24. La alusión al romance Media noche era por filo se inserta a la perfección en la fina red de guińos a frases proverbiales y consejas de personajes literarios típica del Lazarillo. Añádase, para ratificarlo, que «desde 1493, el condado de Arcos pasó a ducado" (Blecua, aparato), y entonces, como observa Aldo Ruffinatto, Las dos caras del "Lazarillo», p. 76, el testimonio "A, una vez más, deja entrever las huellas de una incorrecta enmendación conjetural».

24 Los datos intertextuales vinculan estrechamente la maníaca afectación del pobre escudero ("Con un paso sosegado y el cuerpo derecho [...] echando el cabo de la capa sobre el hombro y a veces so el brazo [...] salió por la puerta [...]. Quien no lo conosciera pensaba ser muy cercano pariente al Conde [...] o a lo menos camarero que le daba de vestir", etcétera) con el Conde Claros del romance, «o a lo menos» con su camarero ("«levantá, mi camarero: / dame vestir y calzar» [...] / diérale calzas de grana, / borceguís de cordobán, / diérale jubón de seda, / aforrado en zarzahán, / diérale un manto rico", etcétera), convirtiendo así en baladí el hecho, sobre el que insiste María del Carmen Vaquero Serrano, "El Conde de Arcos: ¿ Un rasgo más de la toledanidad del Lazarillo de Tormes? ¿Otra ironía?”, Lemir, 12 (2008), pp. 49-92, de que, en pleno Renacimiento, un pariente de los duques de Arcos se autodenominó "conde de Arcos» e inició un procedimiento judicial, auspiciado por otros herederos, que miraba a la obtención de los derechos de propiedad sobre el feudo. 
53.18 en vano fue mi experiencia MBAC Ble

57.3 no solo me mantuviese, mas... MBC esperanza Ve Ruff Ri

No solo no me mantuviese, mas... A Ve Ble Ruff Ri

"Es claro error del arquetipo, que A corrige acertadamente" (Alberto Blecua (ed.), La vida de Lazarillo de Tormes, 1972 (2011), p. 182).

\subsection{3 y bien se empleaba MBAC Ruff}

se le Ve Ble Ri

"La construcción [...] era una frase hecha como bien se le emplea, que Autoridades explica: 'modo de hablar que equivale a con razón le sucede o bien merecido lo tiene' [...]. Podría tratarse de una errata del arquetipo, subsanada por Velasco, puesto que más adelante [...] aparece correctamente: 'Bien se le emplea [...]'”: Alberto Blecua (ed.), La vida de Lazarillo de Tormes, 1972 (2011), p. 184.

Encomendó a que B Ble Ruff Ri

Discusiones recientes por parte de Ruffinatto, Las dos caras del "Lazarillo", p. 68, nota; Blecua, "La edición del Lazarillo de Medina del Campo", p. 293; Rico 2011, p. 233b. Considerando que un todos aparece poco antes, podría ser admisible la enmienda de $\mathrm{B}$, que interpreta el pasaje como *Encomendó a todos que. Los otros registros de encomendar en el Lazarillo se dejan reconducir de hecho a las dos acepciones fundamentales del verbo: a) 'recomendar alguno a otro' (12 "ella me encomendó a él”; 54 "fuime por esa ciudad a encomendarme a las buenas gentes"); b) 'recomendar sobre la posibilidad de hacer o no hacer una cosa', como en nuestro caso (54 "sólamente te encomiendo no sepan que vives comigo, por lo que toca a mi honra”; 73 "encomendó a que muy devotamente suplicasen a Nuestro Señor"). Según observa Rico, el cambio a que / aqui (sobre todo si propiciado por la scriptio continua y por el uso de signos de abreviación) es comunísimo.

Cierto, no se puede ni se debe olvidar la impecable advertencia de Rico, para quien "eligiendo como guías errores que no lo son inequívocamente [...], cualquier estema es posible". Por ello, he dejado fuera de mi elenco algunos casos recogidos por Ruffinatto, dignos de atención, pero quizá no incontrovertibles ${ }^{25}$. Y sin embargo, no me parece que haya dudas sobre el hecho de que, si bien somos deudores de aquel Blecua treintańero por su drástica simplificación de los hipertrofiados estemas producidos durante los ańos sesenta, llenos de inseguras e indemostrables fuentes manuscritas (decisivo el análisis de la puntuación, gracias a la cual Blecua ha remitido elegantemente a modelos impresos las ediciones supervivientes de $1554)^{26}$, le debemos sobre todo a Ruffinatto y a su valoración de un recentior non deterior (entiéndase: no enteramente deterior) como la edición Velasco la segura individuación del arquetipo del Lazarillo: un arquetipo del cual, hasta el 2000, todos hablaban "como si fuera una verdad revela-

25 Aldo Ruffinatto, op. cit., pp. 109 y ss.

26 Alberto Blecua, "Introducción" a La vida de Lazarillo de Tormes, 1972 (2011), pp. 52-59. 
da sin que a nadie se le haya ocurrido nunca ofrecer una prueba concreta de su existencia" 27.

Reforzado por el hecho de que, según Maas, es mejor atacar injustamente un lugar carente de errores que dejar fuera de señalar una posible conjetura $^{28}$, creo que puede ańadirse a la lista de los errores de arquetipo el pasaje que sigue:

37.4 me era luz la hambre, pues dicen que el ingenio con ella se avisa, $\mathrm{y}$ al contrario con la hartura MBAC Ble Ri

En efecto, se puede admitir que el ingenio se avise con la hambre, como leen las cuatro ediciones de 1554, o bien el arquetipo ("el ingenio con ella se avisa”). ¿Pero qué significa "y al contrario con la hartura”? La frase entraña, en cambio, un significado más claro y profundo (y más conforme a la tradición de los refranes evocada por la alusión "pues dicen que...": el hambre aguza el ingenio) si se reconoce en avisa un error facilísimo (en rigor, poligenético) por aviva. Avivar, es decir, "excitar, animar, infundir aliento, espíritu y vivéza, para obrar con mayor vivacidád y vigór" (Diccionario de autoridades), es tradicional predicado de ingenio y de sus parasinónimos: "bebido en poca cantidad [sc. el vino] aviva y adelgaza el ingenio, y augmenta la fuerza"; "la Perspectiva [...] a los que la saben les aviva más la razón y subtiliza el entendimiento"; "aquel aprieto y sequedad del sentido ilustra y aviva el entendimiento, como dice Isaías"; "este humor aviva el ingenio; "mi agudo ingenio se me aviva para decir maravillas"; "Según eso, la necesidad o pobreza, que trae aneja la tristeza, no aviva el ingenio, sino embótale y priva de sus palabras al hombre"; y considérense sobre todo los versos "Porque en la fatiga / La necesidad esfuerza / Y á los ingenios aviva" (he recurrido, como en todos los casos similares, al precioso $C O R D E$ ). "Al contrario", con la hartura el ingenio se cansa, se agota, se ofusca: por mucho que digan los revisionistas, como el autor de

27 Aldo Ruffinatto, op. cit., p. 68.

28 Paul Maas, Crítica del texto (1957), con la presentación de Giorgio Pasquali a la edición italiana, "Mirada retrospectiva" (1956) y una nota de Luciano Canfora a la tercera edición italiana, trad. y notas Andrea Baldissera y Rafael Bonilla Cerezo, Sevilla, UNIA, 2012, \$18; Paolo Trovato, Everything You Always Wanted to Know about Lachmann's Method, p. 267. 
la penúltima cita, la hartura "embota y priva de sus palabras al hombre"29. De cualquier modo, admitiendo también que no todos los errores que acabo de enumerar sean juzgados como tales por el gremio de los estudiosos - a los cuales compete, como en cualquier problema de cierta complejidad, la responsabilidad de verificar la validez de las varias teorías a nuestra disposición acerca de la transmisión textual del Lazarillo_-, la existencia de un arquetipo de la tradición superviviente (identificable, como ya he mencionado, con la princeps o con su casi inmediata reimpresión) se nos antoja fuera de duda, incluso en el supuesto de que se quieran minimizar las secuelas de esta segura deducción ("Tales errores, gráficos o semánticos, apenas nos dicen sino que todas las ediciones derivan de un impreso discretamente descuidado") ${ }^{30}$. El mismo Rico, en unas páginas de gran finura, atribuye por otra parte al editor del arquetipo, más que al autor, también las descoloridas rúbricas que segmentan la narración en bloques temáticos desiguales (Prólogo, Tractado primero..., Tractado segundo... $)^{31}$. Y las deducciones permitidas por el llamado método de Lachmann, llegados a este punto, son la mejor confirmación de la más que razonada hipótesis histórico-cultural del estudioso, fundada en lo que sabemos del proceder habitual de editores y tipógrafos:

La aparición [¿ंo la supervivencia?] de cuatro ediciones en sólo un año - y una de ellas, "añadida" - y en 1555 la publicación en Amberes de una Segunda parte nos certifican que el éxito inicial del Lazarillo fue notable. Un relato tan chispeante no podía dormir demasiado tiempo en las librerías. A la princeps seguiría en unos meses alguna reedición en el mismo formato y al mismo precio ( $\mathrm{y}$, en tal caso, probablemente del mismo editor), y pronto, ya con bastante menos intervalo (como confirma la cercanía de fechas de Alcalá y Medina),

29 Si lo he consultado bien, el lugar no aparece citado entre los errores de arquetipo del Lazarillo por Ruffinatto, que en cambio edita abiva y comenta impecablemente: "Es frase proverbial muy difundida (véase, por ejemplo, Correas, 190a: 'La hambre despierta el ingenio')" (Aldo Ruffinatto, op. cit., p. 182 y nota ccxviii). Del aparato negativo de Ruffinatto ("avisa Am, Me, Bu, Al, Si, M, Pl y Bi") colijo que la lección abiva figuraría en Ve, pero no puedo verificarlo personalmente.

30 Francisco Rico, "Introducción" a Lázaro de Tormes, Lazarillo de Tormes, p. 201.

31 Francisco Rico, ibidem, pp. 96-97. 
módicos paperbacks en menos pliegos ${ }^{32}$.

Un par de palabras también sobre el corrector de la tardía reedición castigada de 1573, Velasco. En la medida en que Velasco es un revisor culto y de elevada profesionalidad, la impresionante destreza con la que su edición se sustrae de errores asimismo muy insidiosos en la tradición superviviente más antigua (a callentar > a acallar, puesto dentro > puesto dentera, avisa $>$ aviva, deyuso > desuso, experiencia > esperanza...) invita a conjeturar, como ya lo ha hecho algún estudioso (Caso González, Rodríguez LópezVásquez, Ruffinatto, Carrasco...), una esporádica contaminación extraestemática (en el sentido de Timpanaro); es decir, a imaginar que Velasco haya utilizado como texto base, aun enmendándola en varios puntos, una fuente perdida de altísima calidad ${ }^{33}$. El quid de la cuestión es: ¡je deberá distinguir entre el arquetipo de la tradición superviviente ("alguna reedición en el mismo formato y al mismo precio” de la primera edición, o sea, una reimpresión apresurada, ya marcada por varios errores) y la copia, más correcta, utilizada por Velasco (un manuscrito más que próximo al original o — solución ciertamente más económica - una copia de la princeps $\mathrm{P}^{*}$, cuya tirada sería seguramente de unos centenares de ejemplares impresos)? Al margen de la calidad de las enmiendas que acabo de rememorar, las mismas que convierten en muy atractivas tales hipótesis, me contento con haber levantado la liebre. Pero también es verdad que si, como parece, la mayor parte de las ediciones de finales del XVI conservadas derivan de C (o de una edición impresa hoy perdida muy similar a $\mathrm{C}$ ), ningún futuro editor del Lazarillo podrá renunciar a una minuciosa revisión de todas las lecciones de Ve cotejables con los testimonios de $1554^{34}$.

\section{Sobre MBA (o SEA, la familia $W$ ) y MB (o SEA, La Subfamilia $Z$ )}

Como los lectores habrán entendido ya perfectamente por sí solos, no es

32 Francisco Rico, ibidem, p. 95.

33 También para la contaminación extra-estemática me permito remitir a Paolo Trovato, Everything You Always Wanted to Know about Lachmann's Method, pp. 134-138.

34 Un útil punto de partida lo constituyen las pesquisas de Alberto Blecua (ed.), La vida de Lazarillo de Tormes, 1972 (2011), pp. 59-67, y Aldo Ruffinatto, op. cit., pp. 125-136. 
mi intención volver a trazar aquí, con pelos y señales, la historia textual de las ediciones del Lazarillo. Pero no puedo por menos que indicar que muchos hallazgos fundamentales son recientes, posteriores al descubrimiento, en 1992, del ejemplar de M, que ha propiciado la recuperación del interés por esta novela en una Espańa que, mientras tanto, se había ido familiarizando con la crítica textual neolachmanniana (gracias sobre todo al excelente manual de Blecua) y con la textual bibliography (gracias a los importantes ensayos de Jaime Moll ${ }^{35}$. Como dicen en Nápoles, nisciuno nasce imparato ('nadie nace sabiendo'), y no creo que el amigo Blecua se enfadará conmigo si observo aquí que su juvenil confirmación de la clasificación AC / B (1972), revalidada — si bien con importantes apostillas_ en su ensayo de 2003 (en el cual propone el estema B / MAC) está fundada en su mayoría sobre lugares no demasiado sólidos. Procuraré demostrar que la oposición C / MBA, ya sostenida por Ruffinatto, resulta más económica.

Examinaré, por lo tanto, los pocos errores comunes (marcados con un asterisco*) y las muchas lecciones características de MBA que remontan, a mi juicio, al subarquetipo que he llamado $w^{36}$. Marcaré con el signo ${ }^{\circ}$ los muchos lugares que repesco de la tabla 1 .

Tabla 3. Errores y lecciones características comunes de $M B A(w)$

*3.4 a las que $w$ a los que C Ble Ruff Ri

En rigor, el error de $w$ es poligenético y fácilmente corregible, pero forma una serie con los otros casos que siguen.

${ }^{\circ} 14.9$ decía que Galeno $w$ Ble Ri

${ }^{\circ} 22.18$ abríame la boca $w$ Ble $\mathrm{Ri}$

• 41.4 me descargó $w$ Ble Ri decía Galeno C Ruff

abriome la boca C Ruff

me descarga C Ruff

35 Me limito a citar, del siempre ańorado Jaime Moll, su fundamental "Problemas bibliográficos del libro del Siglo de Oro", Boletín de la Real Academia Española, 59 (1979), pp. 49-107.

36 Ruffinatto lo llama $y$, pero se trata de una elección poco feliz, puesto que la sigla $y$ ya la había empleado Alberto Blecua (ed.) (La vida del Lazarillo de Tormes, 1972 y 2011) en su estema para referirse al antígrafo (o mejor, como se verá, al presunto antígrafo) de CA. 
44.3 Entonces salimos de la iglesia. A buen paso $w$ Y a buen paso C Ruff Ble $\mathrm{Ri}$

Me parece que la tendencia coupé de $w$ se ajusta menos al estilo del Lazarillo que las volutas más amplias de C: "Entonces salimos de la iglesia y a buen paso tendido comenzamos a ir por una calle abajo".

־49.20 venido el día w Ble Ri veniendo el día C Ruff

Véase sin embargo, a favor de C, la breve discusión de la tabla 1.

${ }^{\circ} 59.11$ con el cual él vino w Ble Ri con el cual vino C Ruff

`63.6 nunca más le quise sufrir, ni sufriría ni sufriré sufría C w Ble Ruff Ri

Como ya he observado, sufriría puede explicarse por repetición o por anticipación del tema sufrir-.

${ }^{\circ} 63.13$ docientas mil maravedís MA Ruff Ri, docien- docientos mil maravedís $\mathrm{C}$ tas veces mil maravedís B Ble

${ }^{\circ} 63.19$ los sacarán de su paso w Ble Ri sacará C Ruff

${ }^{*} 64.4$ y las más y las más ciertas MB Ble Ri, y lo más y las más ciertas C Ruff más cierto $\mathrm{A}$

Tal como he indicado en la tabla 1, la incongruente duplicación de y la más se explicará por ditografía. De ahí también el error crítico de A, que intenta, como de costumbre, corregir lo que no le convence. A la luz del hecho de que el sintagma repetido figura colocado por el generalmente conservador $\mathrm{M}$ en la zona crítica del cambio de línea (y la más / y la más), la ratio tipographica sugiere que se encontrara en la misma posición también en $w$.

${ }^{\circ} 68.4-5$ negocios seglares y visitar w Ble $\mathrm{Ri}$

visitas C Ruff

*72.9-10 y dando crédito w Ri

dando crédito C Ble Ruff

También para Blecua (ed.), La vida del Lazarillo de Tormes (1972 y 2011, p. 184), que igualmente no considera válida la lección de C, "la presencia de $y$ rompe la subordinación exigida".

${ }^{\circ} 73.14$ si en algo podría aprovechar w Ble Ri

podía C Ruff

"This is the only example of a conditional tense in a si-clause that has been noted" (Keniston, apud Ruffinatto, Las dos caras del "Lazarillo", p. 117).

*77.12 Hame sucedido tan ben yo le he usado tan y yo C Ruff Ri facilmente que...w Ble

En el aparato Rico supone persuasivamente "que se perdió una de las dos y griegas contiguas".

*079.9-10 echar maldiciones w Ble Ri echar mil maldiciones C Ruff

El mismo Rico admite que "el mil podría ser de P*”, o bien de la princeps. Y en efecto mil con valor hiperbólico es un estilema del anónimo: "padeciendo mil importunidades", "tenía otras mil formas y maneras para sacar el dinero", "mil cosas buenas me mostró", "mil veces le daba al diablo", "dar en ellos mil besos", "mil servicios", "sufrí mil males", "me hace Dios con ella mil mercedes".

\section{Por sí mismo, ningún error ni ninguna lección caraterística (o por mejor decir, de acuerdo con la terminología que he propuesto en mi manual,}


ningún confirmatory reading de $w$ ) son con seguridad monogenéticos, pero la serie aquí singularizada, convierte, al menos a mi juicio, en más económica la hipótesis del estema bipartido $(w / \mathrm{C})$ respecto al tripartido (A / z/C).

Paso a la subfamilia $z(\mathrm{MB})$. En tradiciones poco prolíficas, no siempre es posible distinguir entre los errores de un testimonio y los errores de una familia. Hasta el afortunado descubrimiento de $\mathrm{M}$ en 1992, el dato más evidente era el relativo al aislamiento de A (la "segunda impresión" de Alcalá de Henares, "nuevamente impressa, corregida, y de nuevo ańadida”). El nuevo testimonio nos permite distinguir entre los errores específicos de $\mathrm{B}$ o de $\mathrm{M}$ y las verosímiles innovaciones que se atribuyen a su ascendente $z$. Veamos por tanto enseguida algunos ejemplos de las innovaciones conjuntivas (marcadas como de costumbre con un asterisco*) y de las lecciones características de $z$.

\section{Tabla 4. Innovaciones conjuntivas y lecciones características de $M B(z)$}

14.8 (I 39) Echaba pronósticos a las preñadas, si traía traían AC Ble Ruff hijo o hija z Ri

14.10 (I 41) para muela, desmayos, males de madre muelas AC Ruff Ri z Ble

18.11 me quebra $\mathrm{z}$ me quebró AC Ble Ruff Ri

*22.3 apertado z apretado AC Ble Ruff Ri

*31.2 corneta z concha A Ble, concheta C Ruff Ri

Blecua y Rico excluyen que la de C sea aquí una lección conservada y la estiman como enmienda del corrector de C. Pero hay que reconocer que corneta (también en su uso común) no se adapta en absoluto al pasaje en cuestión, mientras que el diminutivo de concha, es decir, concheta (registrado solo en el Lazarillo C), resulta "más adherente a los diminutivos italianos que aparecen en otros lugares del texto: pobreto, camareta, silleta" (Ruffinatto, Las dos caras del "Lazarillo", p. 67). Corneta es, en suma, uno de los pocos errores seguramente monogenéticos de la varia lectio del Lazarillo. Y ańádase que es posible que el error sea de $w$ y no de $z$ (en este caso, la lección de $\mathrm{A}$ - no ajeno a intervenciones basadas en conjeturas, como se recordará- sería una enmienda que se apoya en el cercano concha).

*31.19 rogaba... que la echase a la parte $z$ le AC Ble Ruff Ri

*37.10 habiendo... pensando z habiendo... pensado AC Ble Ruff Ri

*39.22 pensando que se iba para mi se envolvía en mí y se AC Ble Ruff Ri mis pajas z

“Errata evidente de B” (o sea, de z), según Blecua, La vida del Lazarillo de Tormes, 1972 (2011), p. 180. 
47.26 fasta hoy z Ble Ruff

*49.15 puerco si sobre z hasta hoy AC Ri

puerco. Y sobre AC Ble Ri Ruff

57.10 una bolsilla de terciopelo raso hecho cien do- echa AC Ruff Ri bleces z Ble

De forma verosímil, hecho se explicará por armonización con los masculinos contiguos (terciopelo raso).

*58.15 de la laceria que les traía, me daban alguna ellas tenían A, les traían C Ruff cosilla z Ble Ri

Como Blecua ("La edición del Lazarillo de Medina del Campo", p. 291), Rico se ciñe a la lección de MB y propone dos significados alternativos, ambos muy sofisticados ('la miseria con que me presentaba', 'la pena que les daba'). Pero la lección de C ("la laceria que les traían", es decir, la miseria que las "mujercillas hilanderas de algodón, que hacían bonetes y vivían par de nosotros”, recibían de los clientes, de los compradores: construcción deliberada y ambiguamente indeterminada) explica tanto la glosa clarificadora de A como el verosímil error de $\mathrm{MB}$, y parece más afín a un matiz semántico de laceria frecuente en el resto del Lazarillo ("metafóricamente, el sustento con que se pasa miserablemente la vida": Menéndez Pidal; o bien una 'modestisíma cantidad de alimento'). Por ejemplo, "me cupo más pan que la laceria que me solía dar", "vi los dos o tres panes comenzados, los que mi amo creyó ser ratonados, y dellos todavía saqué alguna laceria, tocándolos muy ligeramente", "yo tomaba aquella laceria que él me daba, la cual en menos de dos bocados era despachada". En cuanto al verbo, referido al alimento, el padrasto de Lázaro "siempre traía pan, pedazos de carne, y en el invierno leños"; el ciego "traía el pan y todas las otras cosas en un fardel de lienzo"; Lázaro muestra al escudero "el pan y las tripas que en un cabo de la halda traía".

Como puede verse, también en el caso de $z$ hallamos casi siempre errores y lecciones características sospechosas de poligénesis (cambios o trueques de un solo grafema), pero no falta, para tranquilizarnos, un seguro error monogenético como es el de corneta por concheta. Ad abundantiam, en su ensayo "La edición del Lazarillo de Medina del Campo", Blecua señala varios errores de puntuación y descuidos en el uso de las mayúsculas que, a grandes rasgos, singularizan a MB. Y precisa:
Para la puntuación he hecho unas calas en un $80 \%$ del texto y he eliminado aquellos casos en que los hábitos del compone- dor podían coincidir por accidente. Es cierto que, en algunos de los casos seleccionados, las coincidencias podrían ser acci- dentales, pero el número es tal que sobrepasa cualquier cálculo

37 Y no, como ya he advertido, 68.22. 
de probabilidades ${ }^{38}$.

Espigando los ejemplos de Blecua, que no vuelvo a cotejar en los testimonios, añadiré la tabla que sigue:

Tabla 5. Variantes y deslices de puntuación, gráficos y relativos a las mayuisculas caracteristicos de $M B(z)$

4.3 Tulio

8.9 decía, madre $\mathrm{MB}$

37.22 rey $\mathrm{MB}$

38.16 De que vio no le aprovechar nada su remedio (dixo) este arcaz MB

42.5-27 todos me decían tú MB

48.8-9 dixome por mi vida $\mathrm{MB}$

48.17-19 como yo en lo otro sabrosíssimo pan está dixo por Dios, y como MB

49.5-6 la sepas hacer de aquí adelante, púseme MB

53.4 hecho un macías MB

68?? IV 3 frayle MB

71.25-27 El alguacil dixo. Harto MB
Tullio AC

decía: Madre AC

Rey AC

...su remedio, dixo, este arcaz $\mathrm{A}, \ldots$ su remedio, dixo.

Este arcaz C

todos me decían. Tú MB

Dixome. Por mi vida AC

como yo en lo otro. Sabrosíssimo pan está dixo por

Dios. Y como AC

...adelante. Púseme AC

hecho un Macías AC

Frayle AC

...dixo, harto A, ...dixo: harto C

Tal como acabo de mostrar, también esta serie de convergencias, solo formales, y por ello del todo sospechosas de poligénesis (no errores, sino, como mucho, lecciones características, confirmatory readings), refleja la filiación sugerida por la tabla 4.

Tanto el estema de Carrasco como el de Ruffinatto insertan B debajo de $M$, impreso en marzo. Y si no me engaño, una de las contribuciones más señeras del reciente ensayo de Blecua se cifra justamente en la individuación de dos lecciones con seguridad preferibles de BAC, que fueron banalizadas en $\mathrm{M}$ y que, en buena lógica, convierten en inaceptable la

38 Alberto Blecua, "La edición del Lazarillo de Medina del Campo", p. 289. 
filiación $\mathrm{M} \rightarrow \mathrm{B}^{39}$.

Tabla 6. Errores separativos de M según Blecua

21.11-12 om. de M

51.4-5 un poco de lana $\mathrm{M}$

55.20 quel pecador $\mathrm{MC}$ y mandó que fuese por él de vino a la taberna BAC

un copo de lana BAC

aquel pecador $B$, que aquel pecador $A$

Aun reconociendo que el tercer lugar, común a MC, es irrelevante y puede explicarse de diversos modos (la solución más económica al problemita texual parece de cualquier manera quel $=q u$ 'el), los otros dos casos tienen un peso distinto. Si la reconstrucción del técnico copo de lana no es imposible, la innovación, fortuita pero semánticamente sensata, poco de lana podía escapárseles con facilidad también a "transmisores de una competencia lingüística y cultural equiparable a la de los autores". Lo que de veras importa es que "es evidente que la lección por él de vino de BAC es difficilior e irreconstruible ope ingenii por un componedor" ${ }^{40}$. Queda descartado, pues, que $\mathrm{B}$ puede descender de $\mathrm{M}$, del cual es, en cambio y a ciencia cierta, colateral.

En resumidas cuentas, la recuperación y la colación de $M$ permiten individuar una estrecha cosanguinidad entre B y la «nueva» edición, terminada de imprimir en Medina el 1 de marzo de 1554. Ambas remiten a un antígrafo común $z$ y echan por tierra así el valor de muchas lecciones de B, que, antes de 1992, por efecto —diría Rico- de "apreciaciones subjetivas", parecían preferibles a las de A y C. Desautorizadas por el colateral de $\mathrm{B}$, nos parecen lo que son, es decir, innovaciones singulares ${ }^{41}$.

39 Si lo he leído bien, a excepción de 49.14, 63.13, 63.17 (variantes fonéticas, genealógicamente inútiles), no hay en el aparato de Rico otras lecciones singulares de $\mathrm{M}$, que es mucho más conservador que $\mathrm{B}$.

40 Alberto Blecua, "La edición del Lazarillo de Medina del Campo", p. 288. El aparato, por lo general fiable, de Ruffinatto no registra el importante error de M "por el vino", que basta para excluir la posibilidad de que B sea descriptus de M.

41 Un elenco muy amplio, aunque no del todo seguro, de las numerosísimas singulares de B, en Aldo Ruffinatto, op. cit., pp. 120-122. Cito, a título puramente ejemplificador, por las primeras páginas del aparato de Rico 2011: 8.6, 9.3, 15.8-9, 20.7, 
Basten los siguientes ejemplos:

15.9 se cerraba con una argolla de hierro y su candado y su llave B Ble] y llave MAC Ruff Ri

44.12 La cual [casa] tenía la entrada obscura y lóbrega de tal manera que parece que ponía temor a los que en ella entraban B Ble Ri] parescía MAC Ruff

La verosímil omisión del monosílabo $s u$ había sido interpretada por Blecua como un error conjuntivo de $\mathrm{AC}^{42}$, pero el acuerdo de $\mathrm{M}$ con $\mathrm{AC}$ denuncia, en la línea del análisis de Moll, el carácter de arbitrario relleno del posesivo de B, que aparece en c. A $6 r^{43}$. Del mismo modo, en una narración en pasado, no parece factible entender parescía como "error por atracción de tenía y de ponía, que aparecen antes y después" ${ }^{4}$.

\section{Alguna otra observación sobre MB y también sobre C}

Tal vez a causa de las características materiales de C, fruto de su actitud tipográfica innovadora (caracteres romanos y comas según el uso moderno, y no tanto caracteres góticos y dos puntos, o barra oblicua, en latín virgula) y de su formato en $12^{\circ}$ (impreso, pues, diría que sin ningún género

$22.20,23.19,25.19,26.3,26.4,31.2,33.17,37.24,40.2,41.5,42.10,42.19$, $43.16,44.12,7.23$, 48.21, 49.16, 50.2, 50.12, 50.20, 51.22, etcétera. Recuerdo que, como ha demostrado Jaime Moll, "Hacia la primera edición del Lazarillo", B amplifica a menudo por razones tipográficas.

42 Alberto Blecua, "Introducción y notas" a La vida de Lazarillo de Tormes, 1972 (2011), p. 50.

43 "Dos claros casos semejantes [...] encontramos [...] en los folios signatura A 6r y D $4 \mathrm{r}$, páginas que pertenecen también a la forma interna del correspondiente pliego" (Jaime Moll, "Hacia la primera edición del Lazarillo", p. 1053).

44 Alberto Blecua, "Introducción y notas" a La vida de Lazarillo de Tormes, 1972 (2011), p. 180. La lección parecía es adoptada sin vacilación también en la ya citada antología (1899) de Ramón Menéndez Pidal, Antología de prosistas españoles. I, p. 75, cuya apreciable edición parcial se funda sobre el cotejo de los testimonios fundamentales entonces conocidos. 
de duda, cuando el éxito de Lazarillo se antojaba ya incontenible $)^{45}$, casi siempre se ha mirado la edición de Amberes con una desconfianza pareja a la reservada a A, que es declaradamente una segunda impresión, "corregida, y de nuevo añadida" (pero con correcciones de modesta calidad e insertos de poca monta, evidentemente urdidos en la imprenta).

También Blecua opina que algunas lecciones de los dos testimonios son lecciones "corregidas" o "subsanadas por AC". Y si ha interpretado del mismo modo algunas oposiciones AC / MB de naturaleza formal (puntuación, mayúsculas), también ha demostrado de manera irrefutable que, al menos por lo que atañe a la puntuación, A reproduce de forma escrupulosísima sus modelos ("Que Alcalá seguía una edición con puntuación arcaizante lo demuestra el hecho de que al puntuar los fragmentos ańadidos se olvida por completo de los 'dos puntos' y recurre siempre a la 'coma'. El cajista de Alcalá no hace más que copiar lo que tiene delante" ${ }^{46}$. Bien mirado, resulta igualmente difícil imaginar que la impresión de Amberes o su antígrafo introduzca una puntuación y un uso de las mayúsculas más cuidadosos respecto a los de la princeps.

Por lo general (y me permito remitir a mi viejo libro sobre las correcciones editoriales del XV y del XVI en Italia), los correctores se afanan de forma particular en las primeras planas del libro que están editando ${ }^{47}$. Aquí, con una sola excepción (Fulano $C$, fulano w), todas las mayúsculas (al inicio de la frase, en los nombres propios, en las abreviaturas) que el Prólogo presenta en $\mathrm{C}$ se reencuentran en $\mathrm{MB}$, es decir, en el arquetipo: Yo, $Y$ a, Plinio, Mayormente, $Y$ assi, $Y$ quieren, $Y$ a, Tullio, Quien, Predica, O que, Iusto, Suplico, vuestra M., Y pues V.M. Además, al menos en el ejemplar a partir del cual se ha realizado la edición facsimilar de Moreno Báez, C imprime con letra minúscula y, en el primer caso, con

45 Como explica Jaime Moll, "Hacia la primera edición del Lazarillo", pp. 1050-1051, "el proceso que habitualmente se sigue en las reediciones es reducir el número de pliegos, con lo que se abarata su precio". Hoy como ayer, la adopción de un formato menor significa, por lo regular, que el impresor cree tener buenas razones para apostar por un público más largo.

46 Alberto Blecua, "Introducción y notas" a La vida de Lazarillo de Tormes, 1972 (2011), p. 57.

47 Paolo Trovato, Con ogni diligenza corretto. La stampa e le revisioni editoriali dei testi letterari italiani (1470-1570), Bologna, il Mulino, 1991; reed. Ferrara, UnifePress, 2009. 
scriptio continua después de coma (yesto) un comienzo de frase ( $Y$ esto) y la obertura de una sentencia de Tulio (la honra) que M B y A evidencian justamente con la mayúscula inicial (La honra). Si, entonces, esta es la atención del componedor de $\mathrm{C}$ por lo que se refiere a los signos paragrafemáticos en los folios mas expuestos al examen de los potenciales compradores, no hay motivos para pensar que las cosas deberían mejorar en los fascículos sucesivos. El hecho, documentado en la tabla 5, de que en lo sucesivo del texto la puntuación de $\mathrm{MB}$ sea más incorrecta que la de $\mathrm{C}$ se explica de forma más económica por medio del general descuido del interpuesto $z$ que mediante la hipótesis de una fiebre correctora de C o de AC.

Como ya he apuntado, en 2003 Blecua vuelve a reivindicar (en la estela de Cavaliere y otros, entre los cuales también se contaba el joven Rico) la hipótesis de un "subarquetipo corrector" común a A y C. En consecuencia, Blecua interpreta un abanico no muy dilatado de lecciones AC aceptadas por los editores no como lecciones conservadas, sino como correcciones conjeturales del modelo de AC. Los lugares sobre los cuales Blecua funda la conexión $\mathrm{AC}^{48}$ ya se han examinado en alguna ocasión, e incluso se han discutido, aunque solo de forma somera, en las tablas anteriores; los señalo con el signo ${ }^{\circ}$.

\section{Tabla 7. Presuntos errores conjuntivos de AC}

Corneta es considerado un error tanto por Blecua, La vida de Lazarillo de Tormes, 1972 (2011), p. 179, como por Rico 2011, p. 226b, que excluyen sin embargo que las de A y C sean lecciones conservadas; de ahí que las consideren enmiendas. En efecto, la forma concha, que aparece ya en 30.23 ("Cuando al ofertorio estábamos, ninguna blanca en la concha caía que no era dél registrada”), explica la enmienda de A, pero no (como ya he recordado) el diminutivo italianizante de $\mathrm{C}$, del que se hallan varios registros en el Lazarillo. Corneta podría ser un error crítico de $z$ (el modelo utilizado por $\mathrm{MB}$ ), quizá a causa de un cōcheta «desgastado» en su antígrafo, y por ello legible más o menos como cocneta.

Dize C, dexe A

48 Alberto Blecua, "La edición del Lazarillo de Medina del Campo", p. 291. 
Los errores de C y A, como cualquier error que depende de la sustitución de un solo grafema, son (según la taxonomía de Brandoli) típicamente sospechosos de poligénesis y por ello genealógicamente irrelevantes ${ }^{49}$. Además, tanto A (dexe) como C (dize) no transmiten el mismo error.

52.11 lo que por vos no sufrirán $\mathrm{MB}$

sufrirían AC

Por lo menos, variante adiáfora. Pero véase mi comentario a la tabla 1.

58.15 de la laceria que les traía, me daban alguna ellas tenían A, les traían C cosilla... MB

He discutido ya la superioridad de la lección de C en la tabla 4.

${ }^{\circ} 60.5$ venía $\mathrm{MB}($ sic $)$

venian AC (sic)

En realidad, venian (en rigor, poligenético) es error de $\mathrm{MB}$, y la lección venía es la de AC (como se lee en las ediciones del XVI y como se indica en los aparatos de Ruffinatto y Rico). El foco de la escena (una que debia..., la qual iba...) se concentra absolutamente sobre la viuda. La lección, rechazada, de AC ("venía luego par del lecho una que debía ser su mujer del difunto [...] y con ella otras muchas mujeres, la qual iba llorando a grandes voces: -'Marido y señor mío...'”) parece la única aceptable.

\section{${ }^{\circ} 61.31$ no errabades en no quitárselo primero $\mathrm{MB} \quad \mathrm{Om}$. no $\mathrm{AC}$}

La posible omisión del monosílabo podría remontar al arquetipo, de cuya existencia no puede dudarse, o ser poligenética (supresión de un no que sigue a un no muy cercano). Pero como he observado en la tabla 1, el adverbio es necesario solo si, contra la puntuación de los testimonios antiguos, la frase se interpreta como interrogativa.

${ }^{\circ} 64.1-2$ servir con éstos MB servir a éstos AC

Por lo menos, variante adiáfora.

๑64.4 y las más y las más ciertas MB, Y lo más más y las más ciertas $\mathrm{C}$ cierto A

Como ya he indicado en la tabla 1, la ilógica duplicación de y las más se explicará por ditografía. De ahí también el error crítico de A, que aspira, como suele, a corregir lo que no le convence. A la luz del hecho de que el sintagma repetido lo incorpora el aparentemente conservador $M$ en la zona crítica del cambio de línea ( $y$ las más / y las más), la ratio typographica sugiere que se encontrase en la misma posición también en $w$.

\section{Si me equivoco, ninguno de los 8 errores conjuntivos propuestos por el es-}

49 Caterina Brandoli, "Due canoni a confronto: i luoghi di Barbi e lo scrutinio di Petrocchi”, en Nuove prospettive sulla tradizione della Commedia. Una guida filologico linguistica al poema dantesco, ed. Paolo Trovato, Firenze, Cesati, 2007, pp. 99-214. 
tudioso ("Lecturas o correcciones erróneas de $A C$ ”) ${ }^{50}$ sobrevive a un examen. Veamos ahora cómo Blecua desemboca, en 2003, en un estema según el cual MAC estarían en contra de B.

\section{Tabla 8. Presuntos errores conjuntivos de MAC}

Según mi estema — cuya racionalidad, a esta altura, creo haber demostrado ya—, recontaba es lección singular de B, que, como ya he advertido en la tabla 1, se da en la zona crítica del cambio de página.

38.12 cuanto él tejía de día, rompía yo de noche, $y$ en ca B pocos días y noches pusimos la pobre despensa de tal forma, que... MAC

Variante adiáfora, pero singularis, de B.

65.13 de dos meses le alcanzaron lo que él en un año dos en dos B no alcanzara MAC

Error de B, como argumento en la tabla 1 .

Error de arquetipo, evitado por B gracias a una fácil conjetura.

La cosecha parece, aquí, incluso más insignificante. Si verdaderamente $\mathrm{M}$ remontara con el antepasado de $\mathrm{AC}$ a una misma fuente, deberíamos conjeturar que, impasible ante las corruptelas más vistosas del arquetipo (véase supra, tabla 2), el antígrafo de AC se ha esforzado por librarse de todas las innovaciones y de las lecciones adiáforas características de $\mathrm{MB}$ (tabla 4). A fin de cuentas, qué significa el hecho, observado con diligencia por el mismo Blecua, de que " $\mathrm{B}$ y $\mathrm{C}$ discrepan de $\mathrm{A}$ unas ciento diez veces; $\mathrm{A}$ y $\mathrm{C}$ de $\mathrm{B}$ ciento una; y $\mathrm{A}$ y $\mathrm{B}$ de $\mathrm{C}$ treinta y ocho veces, sin contar las erratas evidentes" 51 , sino que las lecciones singulares de $\mathrm{C}$ son menos de la mitad de las que hay en A y B? Hasta que no se demuestre lo contrario, habrá que resignarse a reconocer que $\mathrm{C}$ es un testimonio menos alejado de la princeps de lo que ha tendido a creerse.

50 "La edición del Lazarillo de Medina del Campo", p. 291.

51 Alberto Blecua, "Introducción y notas" a La vida de Lazarillo de Tormes, 1972 (2011), p. 50. 
Por el contrario, como se recordará, también C presenta una pequeña serie de soluciones exclusivas, varias de las cuales (marcadas aquí abajo con el asterisco $^{*}$ ) parecen ser errores separativos:

Tabla 9. Algunos errores separativos y lecciones «singulares» de $C$

25.8 de bajo de los portales MBA

26.1 Olé olé MBA om. de C

Olé C

*78.8 nunca faltaron ni faltarán MBA Ble nunca faltaron C

*78.9 diciendo no sé qué y sí sé que de que veen MBA Ble om. que de $\mathrm{C}$

Tanta la primera como la segunda omisión se explican por homoteleuton.

\section{Conclusiones}

A la luz de lo expuesto, aun cuando los errores verosímilmente monogenéticos sean muy pocos, y se concentren sobre todo a la altura del arquetipo (y sin disponer de una reproducción de la edición de Velasco, de la cual no puedo valorar por tanto la entidad de los reajustes, aun considerándola, prudencialmente, tradición indirecta), creo que se puede concluir que:

1) la tradición del Lazarillo es clasificable, si bien con alguna dificultad, de acuerdo con los instrumenta del método neolachmanniano;

2) el estema que, actualmente, parece adaptarse mejor a todos los datos hasta aquí tomados en consideración es el que propongo al comienzo del $\$ 3(\mathrm{C} / \mathrm{A}+\mathrm{MB})$, que toma en cuenta las aportaciones más relevantes de las clasificaciones propuestas en el nuevo milenio por Ruffinatto y Blecua;

3) por consiguiente, según la ley de la mayoría, todas las lecciones 
singulares de B sin duda se deben rechazar $^{52}$; $y$, como mucho, habrá que apreciar el natural conservadurismo de su colateral $\mathrm{M}$ y del antígrafo de $\mathrm{MB}, z$;

4) donde se puede cotejar con la tradición orgánica, la edición Velasco aporta una serie de lecciones de calidad muy alta, verosímilmente porque ha podido valerse, en varios puntos, de una "fuente" que habría que colocar por encima del arquetipo ${ }^{53}$;

5) en general, excepción hecha de los pocos casos que obligan a consideraciones puntuales (errores indudables de $\mathrm{C}$ o sus lecciones problemáticas), las ediciones actuales menos remotas de la escritura del anónimo son las que más cerca siguen la impresión de Amberes.

Parafraseando la máxima de Churchill con la que abrí estas páginas, se podría sostener, en suma, que, también en casos límites como el representado por el Lazarillo, "the genealogical method is the worst kind of textual criticism except for all the others". Y si el centro de irradiación de la novela fuera España (según consideran la mayoría de los estudiosos), una vez más, parecería confirmarse la advertencia del gran Pasquali acerca de que las áreas laterales (en nuestro caso, Flandes) son tan conservadoras en la historia de las tradiciones textuales como en la lingüística areal.

\section{Apostilla 2016}

Durante la corrección de las pruebas de este trabajo, he cotejado asimismo un interesante artículo de Arturo Rodríguez López-Abadía: "Las dos ediciones del Lazarillo de Amberes de 1553: en 8avo y en 16avo", Etió-

52 Como opinaba el mismo Alberto Blecua, "Introducción y notas" a La vida de Lazarillo de Tormes, 1972 (2011), p. 182, a propósito de ciertas variantes particularmente sospechosas, "si se acepta la lección de AC [en realidad, MAC] deberemos admitir que $B$ no es un texto tan desalińado como se supone y que algunas variantes [...] pueden ser añadidos del impresor".

53 Una interpretación singular, aunque digna de ser perfilada, la ha ofrecido recientemente Pablo Jauralde Pou, op. cit., quien sugiere que Velasco había podido servirse de correcciones de autor, arriesgando así la tesis de la paternidad de un personaje de veras extraordinario como fue don Diego Hurtado de Mendoza. 
picas, 12 (2016), pp. 91-103, que, como si de una matrioska se tratase, contiene referencias a una media docena de aportaciones aparecidas entre 2015 y 2016 sobre el mismo argumento y del mismo autor; o bien de Alfredo Rodríguez López-Vázquez; o bien de ambos, algunos de los cuales legibles en la red.

Moviéndose entre bibliografías dieciochescas, catálogos de venta londinenses del XIX y ediciones del XIX y de principios del XX del Lazarillo, los dos estudiosos brindan unos buenos argumentos a favor de la existencia de una edición de Amberes del 1553 en 16, ya recordada por Brunet («Cependant nos notes nous fournissent l'indication d'une édition d'Anvers, 1553, in-16.»), pero juzgada inverosímil por otros estudiosos, entre los cuales se alista Rico, y se hacen eco de una atestación sobre la existencia de "una edición de 1550 impresa fuera de Espańa» y de otra acerca de una segunda edición de Amberes de 1553, en 8avo.

Personalmente, considero ligeramente fastidioso el desmenudezamiento del problema en tantos artículitos diferentes, que fatalmente presentan una buena dosis de repeticiones, y juzgo un pelo precipitada la sin duda sugestiva e ingeniosa propuesta de identificación de la perdida edición de 1550 con «Estrasburgo, 1550, Augustin Frisius, en dozavo, a 25 emes y titulillos exentos»), según se lee hasta en el título de una de estas contribuciones. No obstante, resulta difícil pensar que todas las pruebas relativas a las ediciones de 1550 y 1553 , que, claro, no sorprenden en exceso (véase, supra, mi nota 4), sean falsas, aunque el estema de la tradición antigua que propone Arturo Rodríguez, cuyos cimientos no parecen todos igualmente sólidos o suficientemente explicitados, tenga que verificarse a base de cotejos más amplios, incluyendo ediciones posteriores a 1554: las cuales podrían depender al menos en parte de la antuerpiense o de las antuerpienses perdidas.

Ni siquiera se antoja metodológicamente correcto - puesto que en 1846 Aribau menciona en su discurso preliminar muchas ediciones ( 1553 , Amberes [= Amb]. - 1554, Burgos [ = B]. - 1554, Amberes (= C). - 1555, Idem. - 1563, Madrid, junto con la Propaladia [= Ve].-1586, Tarragona. - 1587, Milán» etc.: Biblioteca de autores españoles. III. Novelistas anteriores a Cervantes, Madrid, Rivadeneyra, 1846, p. XXI) y, si lo he mirado bien, no aclara sobre cuáles se basó para fijar su texto- imaginar que el buen texto de Buenaventura Aribau coincida sustancialmente con el de 
Amb, como demasiado a menudo los dos Rodríguez sugieren (por ejemplo.: «su texto base [sc. de Aribau] es Amberes 53 y [...] cuando anota variantes de Martín Nucio, indica de dónde proceden, pero cuando anota variantes de Berrillo-Sánchez no lo indica»). Un control que he realizado, tomando como muestra el primer tercio de la novela, prueba que muchísimas lecciones de Aribau se explican simplemente con la difundida edición de Amberes de 1554, C, pero debo reconocer que en muchos casos (por ej., 8.5 acallar Ve y Ruff, 15.2 contraminava Pl (= Amberes 1595) Sa (= Madrid 1599) y Ri, 21.16-17 dentera Ve y Ruff, 22.21 galillo Ve y Ruff, 37.4 aviva / abiva Ve y Ruff) Aribau se remontaba, por encima del arquetipo del que derivan las cuatro ediciones de 1554, a lecciones buenas que se encuentran ora en Ve, ora en $\mathrm{Pl}$, y en consecuencia la hipótesis de que él tuviera acceso a Amberes 1553 parece digna de atenta consideración.

Más en general, no me duelen prendas en reconocerles a Arturo Rodríguez López-Abadía y a Alfredo Rodríguez López-Vázquez el mérito de haber mostrado la necesidad y la urgencia de un estudio imparcial y serio de toda la tradición impresa del Lazarillo, y no solo de las cuatro ediciones de 1554: proyecto, este, que no puede mirar sino con buenos ojos, e incluso con admiración, quien considera que también esta obra maestra puede y debe editarse neolachmannianamente. 